\title{
German Wage Moderation and European Imbalances: Feeding the Global VAR with Theory*
}

\author{
Timo Bettendorf \\ Deutsche Bundesbank
}

\author{
Miguel A. León-Ledesma \\ School of Economics and MaGHiC \\ University of Kent
}

January 2018

\begin{abstract}
German labor market reforms in the 1990s and 2000s are generally believed to have driven the large increase in the dispersion of current account balances in the Euro Area. We investigate this hypothesis quantitatively. We develop a 3-region open economy New Keynesian model with search and matching frictions from which we derive robust sign restrictions for wage bargaining and matching efficiency shocks which we term wage moderation shocks. We impose these restrictions on a Global VAR consisting of Germany and 8 EMU countries to identify a wage moderation shock in Germany. Our results show that, although the German current account was significantly affected by wage moderation shocks, their contribution to European current account imbalances was negligible. We conclude that the German labor market reforms cannot be the lone driver of European imbalances.
\end{abstract}

Keywords: European imbalances, German wage moderation, DSGE, Global VAR, sign restrictions.

JEL classification: F10, F32, F41.

\footnotetext{
*Contact information: Timo Bettendorf, Deutsche Bundesbank, E-Mail: Timo.Bettendorf@bundesbank.de, Wilhelm-Epstein-Strae 14, 60431 Frankfurt am Main, Germany. Miguel León-Ledesma, School of Economics and Macroeconomics Growth and History Centre (MaGHiC), Keynes College, University of Kent, CT27NP, UK, E-mail: m.a.leon-ledesma@kent.ac.uk. The authors are grateful to on anonymous referee, Sandra Eickmeier, Carlo Favero, Reinhold Heinlein, Hans-Martin Krolzig, Eric Leeper, Ron Smith, and Tong Wang as well as participants at the Deutsche Bundesbank research seminar, the 17th International Conference on Macroeconomic Analysis and International Finance, the European Meeting of the Econometric Scociety, as well as the DIW Macroeconometric Workshop for valuable comments and suggestions. This paper represents the authors' personal opinions and does not necessarily reflect the views of the Deutsche Bundesbank or its staff.
} 


\section{Introduction}

It is widely acknowledged that internal current account imbalances in Europe were an important factor behind the financial distress experienced by countries in the Eurozone (see Figure 1). ${ }^{1}$ What is more controversial, however, is what the main drivers of these imbalances were. The IMF (2012) and ILO (2012) mention the increase in German competitiveness since the late 1990s as an important determinant of these imbalances driven by German labor market reforms. Particularly, the decline in German real wages, relative to the Euro Area partners, is cited as a key factor. In contrast, other commentators such as Wyplosz (2013) doubt this view and argue that changes in competitiveness were the consequence and not the cause of the problem.

We test the contribution of shocks to the German labor market, in the form of a reduction in workers' wage bargaining power and/or an increase in matching efficiency, to Eurozone current account imbalances. We make use of a Global VAR (GVAR) for $9 \mathrm{EA}$ countries $^{2}$ in order to measure the spillover effects of these shocks. We identify these shocks in Germany by deriving minimal sign restrictions from a 3-region open economy New Keynesian DSGE model with search and matching frictions. The model features wage bargaining and matching efficiency shocks which we jointly term "wage moderation" shocks. These restrictions are then imposed on the GVAR (see Eickmeier and Ng (2015)) and we analyze the response of Eurozone current accounts and quantify the contribution of these shocks to European imbalances. This identification method follows Canova and Paustian (2011) and has the advantage of being more agnostic about the model structure than estimated DSGE models which often requires knowledge of the exact specification of decision rules and are prone to identification and specification problems. Our approach, in contrast, consists of selecting a set of robust sign restrictions from the theoretical model which are then used to identify wage moderation shocks in the structural GVAR, exploiting the flexibility of the VAR approach. The structural GVAR approach is also best suited for analyzing shock spillovers within the context of multi-country models.

We show that wage moderation shocks in Germany do generally cause an improvement of the domestic current account, while foreign responses are heterogeneous. However, they account for only a very small fraction of the current account balance forecast error variances. Counterfactual analysis shows that the effect of these shocks on the increasing dispersion of the Eurozone current accounts before the crisis is essentially negligible. We conclude that German wage moderation cannot be the lone driver of European imbalances.

Related literature. While the role of the German wage moderation during the

\footnotetext{
${ }^{1}$ See Chen, Milesi-Ferretti, and Tressel (2012) and Hobza and Zeugner (2014) for an overview of trade and capital flows within the Eurozone.

${ }^{2}$ We model Austria, Germany, Spain, Finland, France, Greece, Italy, The Netherlands and Portugal. Due to a lack of data, we do not model Belgium and Luxembourg.
} 
Figure 1: Total current account balance as a percentage of GDP for 9 Eurozone countries (1992Q1-2007Q2)

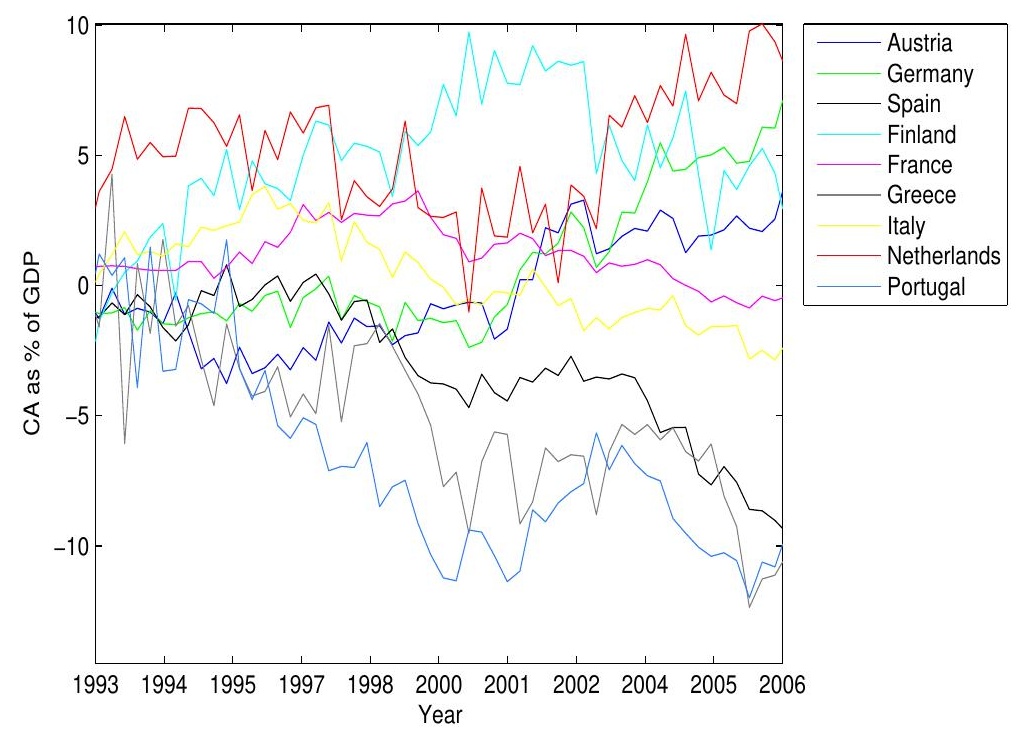

late 1990s and early 2000s has been widely discussed by policy institutions (see IMF (2012) and ILO (2012)), the literature on its international effects is scarcer. As mentioned above, the IMF and ILO as well as Bundesbank (2011) point out that the German wage moderation has increased German competitiveness and thus translated into high current account surpluses, while the current account balances of many other European countries deteriorated. Similar conclusions are reached by Sabbatini and Zollino (2010). Vogel (2011) employs a three-region version of QUEST to investigate possible strategies for re-balancing the Euro Area. Among other strategies, he investigates the theoretical outcome of wage moderation. His results indicate that wage moderation should generally help to re-balance current accounts, as it affects marginal cost of firms, which leads to competitiveness gains. This is in line with Ivanova (2012) who, using panel regressions for 60 countries for the 1970-2009 period, finds that countries with more flexible labor markets tend to have larger current account surpluses.

Gadatsch, Stähler, and Weigert (2014) and Busl and Seymen (2013) make use of policy simulations within a two-country monetary union DSGE model to analyze the effect of German labor market reforms on its current account balance and that of other member states. Their findings are in line with ours as they find a very limited role for these reforms in driving current account imbalances. There is also an important literature on the effects of German labor market reforms on the labor market. Krebs and Scheffel (2013) find that the Hartz IV reform (see below) led to a lower unemployment rate and a higher job finding rate, which supports our assumption that the labor market reforms increased matching efficiency. Fahr 
and Sunde (2009) come to the same conclusion by analyzing the Hartz I/II and III reforms. Closer to our approach, Kollmann, Ratto, Roeger, in't Veld, and Vogel (2015) analyze the German current account balance by estimating a threeregion DSGE model for Germany, the Rest of the Euro Area, and the Rest of the World. ${ }^{3}$ Their results indicate that the German current account surplus is mainly driven by shocks to the German savings rate, the rest of the world's demand for German exports, and supply shocks associated with labor market reforms. An estimated DSGE framework allows for the identification of a large number of structural shocks, which is a clear advantage over our approach. However, as noted above, standard problems such as parameter identification and the assumption of knowledge of the exact data generating process (DGP) of the data often make these estimates fragile. DSGE models also impose more structure on the data and are hence more prone to model mis-specification problems when compared to our more agnostic approach. Finally, a three-region model is unable to trace shock spillovers to specific countries which our GVAR is able to do. Our approach, hence, differs in that we use the flexibility of the SVAR approach combined with minimal theoretical restrictions from a multi-country model.

Overall, thus, the evidence is still controversial regarding the effects of the German labor market reforms on European imbalances through gains in competitiveness and spillover effects on other member states. Our approach focuses on analyzing the effect of these shocks and remains silent about other possible sources of these imbalances. However, the use of a GVAR with minimal theory restrictions provides a more robust data based approach to estimating the dynamic effects of shocks without relying on overly restrictive models. This allows us to assess whether the role of spillovers from German labor market reforms is quantitatively important.

In the following section, we provide a brief overview of German labor market reforms that provide the motivation behind investigating the effects of shocks to workers' bargaining power and matching efficiency. We then present the 3region open economy New Keynesian model with labor market frictions from which we derive robust sign restrictions. Section 4 explains the GVAR model and identification strategy. Sections 5 and 6 present the results and counterfactual analysis, and 7 concludes.

\section{German wage moderation policies}

During the 1980s and 1990s, the job market in Germany provided high protection for employees, with prevalence of permanent jobs with dismissal protection, social insurance, and collective bargaining. Eichorst and Marx (2009) point out

\footnotetext{
${ }^{3}$ See also, for instance, Jacob and Peersman (2013) for an estimated two-country DSGE model to analyze the dynamics of the US trade balance.
} 
that these conditions led to low labor utilization, which affected the service sector in particular. Due to the high requirements for firms, labor intensive personal services, for instance, were mainly provided by family members rather than market services.

In 1996, the country was governed by a coalition of the Christian Democratic Union (CDU) and the Free Democratic Party (FDP). At the time, rigid labor markets were attributed a key role in explaining Germany's poor economic performance. To increase flexibility, the government started reforming the labor market by increasing the maximum duration of fix-term contracts and the threshold number of employees which is required to apply for dismissal protection. Moreover, new minor employment contracts, which have the advantage of lower non-wage labor costs, became frequently used by firms. Additionally, collective bargaining became more flexible, as firms could introduce alternative methods for reducing in working time. With a broader introduction of concession bargaining, firms could dampen wage growth directly (see Eichorst and Marx (2009) and Jacobi and Kluve (2006)).

During the following recovery period, the Social Democratic Party (SPD) and the Alliance 9́/The Greens came to power in 1998. At the beginning of the legislative period, the coalition reintroduced dismissal protection in 1999 as well as a restriction on fixed-term contracts to initial hirings in 2001. With the start of a new recession, however, the government embarked on a new reform to allow for more flexibility. The package of reforms became known as the "Agenda 2010", which also contained the so called "Hartz" labor market reforms. Besides introducing stricter job search monitoring and harsher sanctions such as reductions in unemployment benefits, the government also reduced the period of unemployment insurance pay-outs. However, the main force that increased labor market flexibility was the transition to less bargaining coverage and unionization. The share of workers with opening clauses, which allowed for deviations from the collective contracts, increased strongly. In particular, clauses which allowed for working-time adjustments as well as reductions in nominal and real wages became common. According to the IAB Establishment panel from 2005, almost $29 \%$ of firms in West-Germany and $21 \%$ of East-German firms had these opening clauses in their contracts. Among the firms having opening clauses, $52 \%$ had already made use of the new opening clauses by 2005 (see Eichorst and Marx (2009), Kohaut and Schnabel (2007), and Jacobi and Kluve (2006)).

The effect of these reforms can be seen as a loss in union power and an increase in labor market flexibility that, as discussed in Krebs and Scheffel (2013), also led to a higher job finding rate and thus increased matching efficiency. Hence, we focus on the dynamic transmission of shocks that represent a change in bargaining power and labor market efficiency. To do so, we rationalize these events using the DSGE model with labor market frictions we present in the following section and that we use to impose robust sign restrictions on our structural GVAR. 


\section{A New Keynesian open economy model}

We now introduce the DSGE model that we use to identify wage moderation shocks later on in our GVAR model. We follow the lines of Kollmann, Ratto, Roeger, in't Veld, and Vogel (2015), Gadatsch, Hauzenberger, and Stähler (2016), Krause, Lopez-Salido, and Lubik (2008), Ravenna and Walsh (2011) and Campolmi and Faia (2011) to build a 3-region open economy New Keynesian model with search and matching frictions. The set-up is such that Germany and the Rest of Euro Area (REA) form a two-country model which is augmented by the Rest of the World (RoW). The RoW is modelled exogenously. I.e. we allow feedback effects from the RoW to the Euro Area (EA, including Germany and REA) but the EA will only affect the RoW through changes in relative prices affecting the demand for EA products and hence its trade balance. It displays several standard real and nominal rigidities such as habits in consumption and price rigidities together with search and matching frictions in the labor market. Households consume home produced and imported goods from the other two countries, and can hold home and foreign bonds. For simplicity, and following Kollmann, Ratto, Roeger, in’t Veld, and Vogel (2015), we assume that foreign debt is all denominated in the RoW currency. The interest rate on bonds is debtelastic, allowing us to introduce a risk premium both within the EA and between the EA countries and the RoW. There are preference, labor supply, productivity, wage bargaining, matching efficiency, and monetary policy shocks.

Since the Germany and the REA are both symmetric large open economies, we use the superscript $k=\{G E R, R E A\}$ when explaining the model to denote equations that are replicated for both countries. In the parts where it is necessary for intuition, we will re-introduce the specific country superscript. As Germany's exchange rate regime with the REA changed throughout the period considered, we present two versions of the model to check whether the sign restrictions are robust the monetary regime change. The first version is for the case of flexible nominal exchange rates and the second for the case of a monetary union. The following sub-sections explain the GER and REA blocks of the model. The RoW will be presented afterwards.

\subsection{Labor market: search and matching}

Firms fill open positions with identical workers by publishing adverts and screening, which is cost intensive. The number of matches is given by the Cobb-Douglas function

$$
M_{t}^{k}=\bar{m}_{t}^{k} S_{t}^{k^{\nu}} V_{t}^{k^{1-\nu}}
$$

where $M_{t}^{k}$ is the share of matches and $S_{t}^{k}, V_{t}^{k}$ the shares of searching workers and vacant positions. $\bar{m}_{t}^{k}$ is the stochastic efficiency of the matching function that follows the law of motion: $\log \left(\bar{m}_{t}^{k}\right)=\left(1-\rho^{m}\right) \log \left(\bar{m}^{k, S S}\right)+\rho^{m} \log \left(\bar{m}_{t-1}^{k}\right)+$ 
$\epsilon_{t}^{m}$, where $\epsilon_{t}^{m}$ a shock to matching efficiency. $\nu$, with $0<\nu<1$, stands for the elasticity of the matching function. A firm fills a position with probability $q\left(\theta_{t}^{k}\right)=\frac{M_{t}^{k}}{V_{t}^{k}}=\bar{m}_{t}^{k} \theta_{t}^{k^{-\nu}}$, which is decreasing in labor market tightness $\theta_{t}^{k}=$ $\frac{V_{t}^{k}}{S_{t}^{k}}$ and increasing in matching efficiency. Thus, a positive shock to matching efficiency increases the probability of firms filling vacancies for a given labor market tightness. We will later use this shock as one of the two consequences of the German labor market reforms. The law of motion for aggregate employment is given by

$$
N_{t}^{k}=(1-\rho) N_{t-1}^{k}+M_{t}^{k}=(1-\rho) N_{t-1}^{k}+\theta_{t}^{k} q\left(\theta_{t}^{k}\right) S_{t}^{k}
$$

where $\rho$ is the exogenous job separation rate. The number of searching workers is thus given by

$$
S_{t}^{k}=1-(1-\rho) N_{t-1}^{k}
$$

An unemployed worker finds a position with probability $p\left(\theta_{t}\right)=\frac{M_{t}}{S_{t}}=\theta_{t} q\left(\theta_{t}\right)$, which is increasing in labor market tightness. The unemployment rate is defined as $U_{t}^{k}=\left(1-N_{t}^{k}\right)$.

\subsection{The household}

Each household in country $k$ is a continuum of workers that is distributed over the unit interval. A household maximizes lifetime utility

$$
J_{0}^{H}=E_{0} \sum_{t=0}^{\infty} \beta^{t} \epsilon_{t}^{k^{P}}\left\{\frac{\left(C_{t}^{k}-\omega C_{t-1}^{k}\right)^{1-\sigma}}{1-\sigma}-\epsilon_{t}^{k^{L}} N_{t}^{k} \frac{H_{t}^{k^{1+\varphi}}}{1+\varphi}\right\}
$$

where $\beta$ denotes the discount factor, $C_{t}^{k}$ is the composite consumption aggregator, $\omega C_{t-1}^{k}$ an index of external habits, $N_{t}^{k}$ is labor, $H_{t}^{k}$ hours worked, $\sigma$ the elasticity of intertemporal substitution, and $\varphi$ the inverse Frisch elasticity of labor supply. $\epsilon_{t}^{k^{P}}$ and $\epsilon_{t}^{k^{L}}$ are preference and labor supply shocks respectively that affect the discount factor and the dis-utility of work. We assume that both shocks follow an $\operatorname{AR}(1)$ process with persistence $\rho_{L}$ and $\rho_{P}$ respectively. The household faces the following (real) budget constraint:

$$
\begin{aligned}
C_{t}^{k}+\frac{D_{t}^{k}}{P_{t}^{k}}+ & \frac{e_{R o W, t}^{k} B_{F, t}^{k}}{P_{t}^{k}}=\frac{D_{t-1}^{k}}{P_{t}^{k}}\left(1+R_{t-1}^{k}\right)+ \\
& \frac{e_{R o W, t}^{k} B_{F, t-1}^{k}}{P_{t}^{k}}\left(1+R_{t-1}^{R o W}\right)+W_{t}^{k} N_{t}^{k} H_{t}^{k}+\left(1-N_{t}^{k}\right) b^{k}+\frac{\Pi_{t}^{k}}{P_{t}^{k}}+T_{t}^{k}
\end{aligned}
$$


as well as

$$
N_{t}^{k}=(1-\rho) N_{t-1}^{k}+\theta_{t}^{k} q_{t}\left(\theta_{t}^{k}\right) S_{t}^{k}
$$

Here, $P_{t}^{k}$ denotes the aggregate price level, $D_{t}^{k}$ domestic bond holdings, $B_{F, t}^{k}$ denotes holdings of country $k$ 's bonds by foreigners (that is RoW and the other country in the EA), $e_{\text {RoW,t }}^{k}$ the nominal exchange ${ }^{4}$ rate defined as units of domestic currency per unit of foreign currency, $R_{t}^{k}$ the domestic interest rate, $R_{t}^{R o W}$ the foreign (RoW) interest rate, $W_{t}^{k}$ real wages, $b^{k}$ unemployment benefits of the $U_{t}^{k}=\left(1-N_{t}^{k}\right)$ unemployed household members, $\Pi_{t}^{k}$ profits from the firms and $T_{t}^{k}$ transfers or lump sum taxes.

Households consume home and foreign produced differentiated varieties. Each of these varieties $i$ are combined using a Dixit-Stiglitz aggregator:

$$
\begin{aligned}
C_{G E R, t}^{k} & =\left[\int_{0}^{1} C_{G E R, t}^{k}(i)^{\frac{\epsilon-1}{\epsilon}} \mathrm{d} i\right]^{\frac{\epsilon}{\epsilon-1}}, \\
C_{R E A, t}^{k} & =\left[\int_{0}^{1} C_{R E A, t}^{k}(i)^{\frac{\epsilon-1}{\epsilon}} \mathrm{d} i\right]^{\frac{\epsilon}{\epsilon-1}}, \\
\text { and } C_{R o W, t}^{k} & =\left[\int_{0}^{1} C_{R o W, t}^{k}(i)^{\frac{\epsilon-1}{\epsilon}} \mathrm{d} i\right]^{\frac{\epsilon}{\epsilon-1}},
\end{aligned}
$$

where $\epsilon>1$ stands for the home and foreign elasticities of substitution between differentiated goods. The composite aggregate consumption index is defined by

$$
C_{t}^{k}=\left[n_{G E R}^{k}{ }^{\frac{1}{\varpi}} C_{G E R, t}^{k}{ }^{\frac{\varpi-1}{\varpi}}+n_{R E A^{k}}^{\frac{1}{\varpi}} C_{R E A, t}^{k}{ }^{\frac{\varpi-1}{\varpi}}+n_{R o W}^{k} C_{R o W, t}^{\frac{1}{\varpi}}\right]^{\frac{\varpi-1}{\varpi}},
$$

where $C_{G E R, t}^{k}, C_{R E A, t}^{k}$ and $C_{R o W, t}^{k}$ denote home consumption of German, REA and RoW goods, respectively. $\varpi$ stands for the Armington elasticity of substitution between home and foreign goods. Coefficients $n_{k}^{k}$ can be interpreted as the degree of home bias in consumption. $n_{R E A}^{G E R}$, for example, refers to the share of REA goods in the German consumption basket when relative prices equal unity. ${ }^{5}$ The consumption index is thus a generalized mean of consumption of home goods and foreign goods with the weights given by $n$.

With symmetric equilibrium, households choose domestic and foreign tradable goods to minimize expenditure leading to the following static demand func-

\footnotetext{
${ }^{4}$ Note that cross rates imply that $e_{R E A, t}^{G E R}=e_{R o W}^{G E R} \frac{1}{e_{R o W}^{R E A}}$. As mentioned above, we also assume that international debt is issued in the RoW currency for simplicity. $n_{R E A}^{R o W}$.

${ }^{5}$ We assume that $n_{G E R}^{G E R}=n_{R E A}^{R E A}=n_{R o W}^{R o W}, n_{R E A}^{G E R}=n_{G E R}^{R E A}$ and $n_{R o W}^{G E R}=n_{R o W}^{R E A}=n_{G E R}^{R o W}=$
} 
tions:

$$
\begin{aligned}
C_{k, t}^{k} & =n_{k}^{k}\left(\frac{P_{k, t}^{k}}{P_{t}^{k}}\right)^{-\varpi} C_{t}^{k}, \\
C_{R o W, t}^{k} & =n_{R o W}^{k}\left(\frac{\left(e_{R o W, t}^{k} P_{t}^{R o W}\right)}{P_{t}^{k}}\right){ }^{-\varpi} C_{t}^{k}, \\
C_{R E A, t}^{G E R} & =n_{R E A}^{G E R}\left(\frac{\left(e_{R E A, t}^{G E R} P_{R E A, t}^{R E A}\right)}{P_{t}^{G E R}}\right)^{-\varpi} C_{t}^{G E R}, \\
C_{G E R, t}^{R E A} & =n_{G E R}^{R E A}\left(\frac{\left(e_{G E R, t}^{R E A} P_{G E R, t}^{G E R}\right)}{P_{t}^{R E A}}\right)^{-\varpi} C_{t}^{R E A} .
\end{aligned}
$$

The consumer price index (CPI) is defined as

$$
\begin{aligned}
P_{t}^{G E R} & =\left[n_{G E R}^{G E R} P_{G E R, t}^{G E R}{ }^{(1-\varpi)}+n_{R E A}^{G E R}\left(e_{t, R E A}^{G E R} P_{R E A, t}^{R E A}\right)^{(1-\varpi)}+n_{R o W}^{G E R}\left(e_{t, R o W}^{G E R} P_{t}^{R o W}\right)^{(1-\varpi)}\right]^{\frac{1}{1-\varpi}} \\
P_{t}^{R E A} & =\left[n_{R E A}^{R E A} P_{R E A, t}^{R E A}{ }^{(1-\varpi)}+n_{R E A}^{R E A}\left(e_{t, G E R}^{R E A} P_{G E R, t}^{G E R}\right)^{(1-\varpi)}+n_{R o W}^{R E A}\left(e_{t, R o W}^{R E A} P_{t}^{R o W}\right)^{(1-\varpi)}\right]^{\frac{1}{1-\varpi}}(17)
\end{aligned}
$$

Each household chooses $C_{t}^{k}, D_{t}^{k}$ and $B_{t, F}^{k}$. The corresponding FOCs are given by

$$
\begin{gathered}
\frac{\partial J_{0}^{H}(i)}{\partial C_{t}^{k}} \Rightarrow \lambda_{t}^{k}=\epsilon_{t}^{k P}\left(C_{t}^{k}-\omega C_{t-1}^{k}\right)^{-\sigma}, \\
\frac{\partial J_{0}^{H}(i)}{\partial D_{t}^{k}} \Rightarrow \frac{\lambda_{t}^{k}}{P_{t}^{k}}=\frac{\lambda_{t+1}^{k}}{P_{t+1}^{k}}\left(1+R_{t}^{k}\right) \beta,
\end{gathered}
$$

and

$$
\frac{\partial J_{0}^{H}(i)}{\partial B_{t, F}^{k}} \Rightarrow \frac{\lambda_{t}^{k} e_{R o W, t}^{k}}{P_{t}^{k}}=\frac{\lambda_{t+1}^{k} e_{R o W, t+1}^{k}}{P_{t+1}^{k}}\left(1+R_{t}^{R o W}\right) \beta .
$$

These optimality conditions provide the Euler equation:

$$
\epsilon_{t}^{k^{P}}\left(C_{t}^{k}-\omega C_{t-1}^{k}\right)^{-\sigma}=\beta \frac{\left(1+R_{t}^{k}\right)}{\pi_{t+1}^{k}} \epsilon_{t+1}^{k}{ }^{P}\left(C_{t+1}^{k}-\omega C_{t}^{k}\right)^{-\sigma} .
$$

As suggested by Kollmann (2002) and Schmitt-Grohe and Uribe (2003), we introduce $X_{R o W, t}^{G E R}$ and $X_{R o W, t}^{R E A}$ as foreign debt elastic interest rate premium to ensure 
stationarity of the stock of net foreign assets. Since asset markets clear such that

$$
B_{F, t}^{G E R}+B_{F, t}^{R E A}=B_{F, t}^{E A}=-B_{F, t}^{R o W}
$$

the risk premia can be defined as:

$$
\begin{aligned}
& X_{R o W, t}^{G E R}=e^{-\gamma\left(B_{t, F}^{R E A}+B_{F, t}^{R o W}\right)}, \\
& X_{R o W, t}^{R E A}=e^{-\gamma\left(B_{t, F}^{G E R}+B_{F, t}^{R o W}\right)},
\end{aligned}
$$

where $\gamma$ is the debt-elasticity of the risk premium. Combining the FOCs for $D_{t}^{k}$ and $B_{t, F}^{k}$ and the risk premia defined above, gves us the UIP condition: ${ }^{6}$

$$
R_{t}^{k}=R_{t}^{R o W} X_{R o W, t}^{k} \frac{e_{R o W, t+1}^{k}}{e_{R o W, t}^{k}}
$$

\subsection{Firms}

Firms operate in monopolisticaly competitive markets as they produce differentiated goods and produce using only labor with a diminishing returns production function:

$$
Y_{t}^{k}(i)=A_{t}^{k}\left(N_{t}^{k}(i) H_{t}^{k}(i)\right)^{v}
$$

where $v$ governs the degree of diminishing returns to labor and $A_{t}$ a technology process that follows an autoregressive law of motion: $\log \left(A_{t}^{k}\right)=\rho_{a} \log \left(A_{t-1}^{k}\right)+\epsilon_{t}^{k^{A}}$.

Firms can sell their output for consumption at home or abroad. We assume producer currency pricing and account for price stickiness by assuming that firms are subject to quadratic price adjustment costs à la Rotemberg (1982). Firms maximize real discounted future profits:

$$
\begin{aligned}
J_{0}^{F}(i) & =E_{0} \sum_{t=0}^{\infty} \beta^{t} \frac{\lambda_{t}^{k} / \chi_{t}^{k}}{\lambda_{0}^{k} / \chi_{0}^{k}}\left[\left(\frac{P_{k, t}^{k}(i)}{P_{k, t}^{k}}\right)^{1-\epsilon} C_{w, t}^{k}\right. \\
& -\chi_{t}^{k} W_{t}^{k}(i) N_{t}^{k}(i) H_{t}^{k}(i)-\kappa V_{t}^{k}(i) \\
& \left.-\frac{\psi}{2}\left(\frac{P_{k, t}^{k}(i)}{P_{k, t-1}^{k}(i)}-1\right)^{2} Y_{t}^{k}(i)\right]
\end{aligned}
$$

where $\psi$ is the price adjustment cost coefficient. Since firms take only domestic

\footnotetext{
${ }^{6}$ This UIP condition for each country $k$ with the RoW implicitly defines a UIP condition for countries within the EA.
} 
prices into account, we correct the discount factor by $\chi_{t}^{k}=\frac{P_{t}^{k}}{P_{k, t}^{k}}$, which can be interpreted as a proxy for the terms of trade (see Campolmi and Faia (2011)). Hence, the stochastic discount factor discounts future profits taking only domestic prices into account. It provides today's (period $t=0$ ) value of future profits in terms of marginal utility of consumption adjusted by home prices. Parameter $\kappa$ denotes the hiring costs, while world consumption of the home good is given by $C_{w, t}^{k}=C_{k, t}^{k}+C_{k, t}^{R E A}+C_{k, t}^{R o W}$ if $k=\mathrm{GER}$ or $C_{w, t}^{k}=C_{k, t}^{k}+C_{k, t}^{G E R}+C_{k, t}^{R o W}$ if $k=$ REA. Firms maximize (17) subject to the law of motion for employment

$$
N_{t}^{k}(i)=(1-\rho) N_{t-1}^{k}(i)+q\left(\theta_{t}^{k}\right) V(i)_{t}^{k}
$$

and that supply equals demand (from (26))

$$
A_{t}^{k}\left(N_{t}^{k}(i) H_{t}^{k}(i)\right)^{v}=\left(\frac{P_{k, t}^{k}(i)}{P_{k, t}^{k}}\right)^{-\epsilon} C_{w, t}^{k}
$$

Firms choose $P_{k, t}^{k}(i), N_{t}^{k}(i), V_{t}^{k}(i)$ and bargain for $W_{t}^{k}(i)$ and $H_{t}^{k}(i)$. We interpret the Lagrange multiplier of (29) as marginal costs $\left(m c_{t}^{k}\right)$ and the multiplier related to $(28)$ as the marginal value of one worker $\left(\mu_{t}^{k}\right)$. First order conditions are given by:

$$
\begin{aligned}
& \frac{\partial J_{0}^{F}(i)}{\partial P_{k, t}^{k}(i)} \Rightarrow 0=(1-\epsilon)\left(\frac{P_{k, t}^{k}(i)}{P_{k, t}^{k}}\right)^{-\epsilon}\left(\frac{C_{w, t}^{k}}{P_{k, t}^{k}}\right) \\
&+m c_{t}^{k} \epsilon\left(\frac{P_{k, t}^{k}(i)}{P_{k, t}^{k}}\right)^{-1-\epsilon}\left(\frac{C_{w, t}^{k}}{P_{k, t}^{k}}\right) \\
&-\psi\left(\frac{P_{k, t}^{k}(i)}{P_{k, t-1}^{k}(i)}-1\right)\left(\frac{Y_{t}^{k}}{P_{k, t-1}^{k}(i)}\right) \\
&+\beta \psi \frac{\lambda_{t+1}^{k} / \chi_{t+1}^{k}}{\lambda_{t}^{k} / \chi_{t}^{k}}\left(\frac{P_{k, t+1}^{k}(i)}{P_{k, t}^{k}(i)}-1\right)\left(\frac{P_{k, t+1}^{k}(i) Y_{t+1}^{k}}{P_{k, t}^{k}(i)}\right) \\
& \frac{\partial J_{0}^{F}(i)}{\partial N_{t}^{k}(i)} \Rightarrow \mu_{t}^{k}=\beta \frac{\lambda_{t+1}^{k} / \chi_{t+1}^{k}}{\lambda_{t}^{k} / \chi_{t}^{k}} \mu_{t+1}^{k}(1-\rho)+m c_{t}^{k} A_{t}^{k} v N_{t}^{k v-1} H_{t}^{k v}-\chi_{t}^{k} W_{t}^{k} H_{t}^{k} \\
& \frac{\partial J_{0}^{F}(i)}{\partial V_{t}^{k}(i)} \Rightarrow \mu_{t}^{k}=\frac{\kappa}{q\left(\theta_{t}^{k}\right)}
\end{aligned}
$$


Since all firms set the same price in equilibrium (i.e. $P_{k, t}^{k}(i)=P_{k, t}^{k}$ ), we may rewrite $\frac{\partial J_{0}^{F}(i)}{\partial P_{k, t}^{k}(i)}$, which yields (after multiplying by $\left(\frac{P_{k, t}^{k}}{Y_{t}^{k}}\right)$ )

$$
\begin{aligned}
\psi\left(\pi_{k, t}^{k}-1\right) \pi_{k, t}^{k} & =\frac{C_{w, t}^{k}}{Y_{t}^{k}}\left(1-\epsilon+m c_{t}^{k} \epsilon\right)+\beta \psi \frac{\lambda_{t+1}^{k} / \chi_{t+1}^{k}}{\lambda_{t}^{k} / \chi_{t}^{k}}\left(\pi_{k, t+1}^{k}-1\right) \pi_{k, t+1}^{k}\left(\frac{Y_{t+1}^{k}}{Y_{t}^{k}}\right), \\
\text { where } \pi_{k, t}^{k} & =\frac{P_{k, t}^{k}}{P_{k, t-1}^{k}} .
\end{aligned}
$$

\subsection{Wage bargaining}

Firms and workers negotiate wages according to a Nash bargaining process, such that the wage is determined by solving the problem

$$
\max _{W_{t}^{k}, H_{t}^{k}}\left(\frac{1}{\lambda_{t}^{k}} \frac{\partial J_{t}^{H}\left(N_{t}^{k}\right)}{\partial N_{t}^{k}}\right)^{\eta_{t}^{k}}\left(\frac{\partial J_{t}^{F}\left(N_{t}^{k}\right)}{\partial N_{t}^{k}}\right)^{1-\eta_{t}^{k}}
$$

where $\frac{\partial J_{t}^{H}\left(N_{t}^{k}\right)}{\partial N_{t}^{k}}$ denotes the households' marginal utility of supplying an additional unit of labor, whereas $\frac{\partial J_{t}^{F}\left(N_{t}^{k}\right)}{\partial N_{t}^{k}}$ denotes the firms' marginal utility of hiring an additional unit of labor. The parameter $\eta_{t}^{k}$ can be interpreted as the bargaining power of households.

We assume that $\log \left(\eta_{t}^{k}\right)=\left(1-\rho_{\eta}\right) \log \left(\eta^{k^{S S}}\right)+\rho_{\eta} \log \left(\eta_{t-1}^{k}\right)+\varepsilon_{t}^{k^{\eta}}($ in $\operatorname{logs})$ with $0 \leq \eta_{t}^{k} \leq 1$. This, together with the matching efficiency shock, is one of the key shocks we will be focusing on. A negative shock to $\eta_{t}$ gives the households' marginal utility of supplying an additional unit of labor a lower weight in the Nash bargaining problem, which is equivalent to a lower bargaining power of labor unions. As discussed above, in Germany, this happened mainly through a shift from collective bargaining to concession bargaining and the introduction of opening clauses (see Section (2)).

The first order conditions are given by:

$$
\begin{aligned}
\frac{\partial J_{t}^{H}\left(N_{t}^{k}\right)}{\partial N_{t}^{k}} \Rightarrow \zeta_{t}^{k}= & \lambda_{t}^{k}\left(W_{t}^{k} H_{t}^{k}-b^{k}\right)-\epsilon_{t}^{k^{L}} \epsilon_{t}^{k^{P}} \frac{H_{t}^{k^{1+\varphi}}}{1+\varphi} \\
& +\beta \zeta_{t+1}^{k}(1-\rho)\left(1-\theta_{t+1}^{k} q\left(\theta_{t+1}^{k}\right)\right) \\
= & \lambda_{t}^{k}\left(W_{t}^{k} H_{t}^{k}-b^{k}\right)-\epsilon_{t}^{k^{L}} \epsilon_{t}^{k^{P}} \frac{H_{t}^{k^{1+\varphi}}}{1+\varphi} \\
& +\beta \frac{\partial J_{t}^{H}\left(N_{t}^{k}\right)}{\partial N_{t}^{k}}(1-\rho)\left(1-\theta_{t+1}^{k} q\left(\theta_{t+1}^{k}\right)\right)
\end{aligned}
$$




$$
\begin{aligned}
\frac{\partial J_{t}^{F}\left(N_{t}^{k}\right)}{\partial N_{t}^{k}} \Rightarrow \mu_{t}^{k}= & \beta \frac{\lambda_{t+1}^{k} / \chi_{t+1}^{k}}{\lambda_{t}^{k} / \chi_{t}^{k}} \mu_{t+1}^{k}(1-\rho)+m c_{t}^{k} A_{t}^{k} v N_{t}^{k^{v-1}} H_{t}^{k^{v}}-\chi_{t}^{k} W_{t}^{k}\left(\mathbb{B}_{t}^{k} 7\right) \\
= & \beta \frac{\lambda_{t+1}^{k} \chi_{t+1}^{k}}{\lambda_{t}^{k} / \chi_{t}^{k}} \frac{\partial J_{t}^{F}\left(N_{t+1}^{k}\right)}{\partial N_{t+1}^{k}}(1-\rho) \\
& +m c_{t}^{k} A_{t}^{k} v N_{t}^{k^{v-1}} H_{t}^{k^{v}}-\chi_{t}^{k} W_{t}^{k} H_{t}^{k}
\end{aligned}
$$

We derive the equations for wages and hours in Appendix B. For wages, we obtain

$$
W_{t}^{k} H_{t}^{k}=\delta_{t}^{k}+b^{k}+\frac{1}{\lambda_{t}^{k}} \epsilon_{t}^{k^{L}} \epsilon_{t}^{k} P \frac{H_{t}^{k^{1+\varphi}}}{1+\varphi}-E_{t}\left[\beta(1-\rho)\left(1-\theta_{t+1}^{k} q\left(\theta_{t+1}^{k}\right)\right) \delta_{t+1}^{k}\right],
$$

where

$$
\delta_{t}^{k}=\frac{\eta_{t}^{k}}{\left(1-\eta_{t}^{k}\right)} \frac{1}{\chi_{t}^{k}} \frac{\kappa}{q\left(\theta_{t}^{k}\right)} .
$$

Hours are determined by

$$
H_{t}^{k}=\left(\frac{m c_{t}^{k} A_{t}^{k} v^{2} N_{t}^{k^{v-1}}}{\chi_{t}^{k} \epsilon_{t}^{k} \epsilon_{t}^{k^{P}} \lambda_{t}^{k}}\right)^{\frac{1}{1+\varphi-v}}
$$

\subsection{Market clearing}

The goods market clearing condition is given by

$$
Y_{t}^{G E R}=C_{G E R, t}^{G E R}+C_{R E A, t}^{G E R}+C_{R o W, t}^{G E R}+\kappa V_{t}^{G E R}+\frac{\psi}{2}\left(\frac{P_{H, t}^{G E R}}{P_{H, t-1}^{G E R}}-1\right)^{2} Y_{t}^{G E R}
$$

and

$$
Y_{t}^{R E A}=C_{G E R, t}^{R E A}+C_{R E A, t}^{R E A}+C_{R o W, t}^{R E A}+\kappa V_{t}^{R E A}+\frac{\psi}{2}\left(\frac{P_{H, t}^{R E A}}{P_{H, t-1}^{R E A}}-1\right)^{2} Y_{t}^{R E A}
$$

Production is used in consumption of home and foreign goods, spending on vacancy costs, and the cost of the quadratic price adjustment. 


\subsection{The current account and the real exchange rate}

The trade balance $\left(T B_{t}^{k}\right)$ is defined as:

$$
\frac{e_{R o W, t}^{k} B_{t, F}^{k}}{P_{t}^{k}}-R_{t-1}^{R o W} \frac{e_{R o W, t}^{k} B_{t-1, F}^{k}}{P_{t-1}^{k}}=T B_{t}^{k}
$$

where $T B_{t}^{k}$ is derived as

$$
T B_{t}^{k}=\frac{P_{k, t}}{P_{t}}\left(Y_{t}^{k}-\kappa V_{t}^{k}-\frac{\psi}{2}\left(\frac{P_{k, t}^{k}}{P_{k, t-1}^{k}}-1\right)^{2} Y_{t}^{k}\right)-C_{t}^{k} .
$$

World goods market clearing implies that

$$
T B_{t}^{G E R}+T B_{t}^{R E A}=-T B_{t}^{R o W} .
$$

The current account is defined as

$$
C A_{t}^{k}=\frac{e_{R o W, t}^{k} B_{t, F}^{k}}{P_{t}^{k}}-\frac{e_{R o W, t}^{k} B_{t-1, F}^{k}}{P_{t}^{k}}
$$

As mentioned above, we assume that the law of one price (LOP) holds and that the Euro Area is too small to affect prices in the rest of the world, which are therefore exogenously determined. We define the German real exchange rate vis-à-vis REA and RoW as

$$
\begin{gathered}
\mathcal{Q}_{R E A, t}^{G E R}=\frac{e_{R E A, t}^{G E R} P_{t}^{R E A}}{P_{t}^{G E R}}, \\
\mathcal{Q}_{R o W, t}^{G E R}=\frac{e_{R o W, t}^{G E R} P_{t}^{R o W}}{P_{t}^{G E R}},
\end{gathered}
$$

which implies that an increase in $\mathcal{Q}_{t}$ is a (German) depreciation.

\subsection{Monetary and fiscal policies}

Monetary policy makers follow a Taylor rule

$$
\left(\frac{R_{t}^{k}}{R^{k, S S}}\right)=\left(\frac{R_{t-1}^{k}}{R^{k, S S}}\right)^{\tau_{r}^{k}}\left[\left(\frac{\pi_{t}^{k}}{\pi^{k, S S}}\right)^{\tau_{\pi}^{k}}\left(\frac{Y_{t}^{k}}{Y^{k, S S}}\right)^{\tau_{y}^{k}}\right]^{1-\tau_{r}^{k}} \epsilon_{t}^{k}
$$


where the superscript $S S$ denotes the steady state value of a variable. The central bank targets the deviations of inflation and output from their steady states according to the policy weights $\tau_{\pi}^{k}$ and $\tau_{y}^{k}$. Moreover, the monetary authorities smooth the law of motion of the nominal interest rate according to the smoothing parameter $\tau_{r}^{k} . \epsilon_{t}^{k}$ is a monetary policy shock.

Fiscal policy faces the constraint

$$
\frac{D_{t}^{k}}{P_{t}^{k}}=R_{t-1}^{k} \frac{D_{t-1}^{k}}{P_{t}^{k}}+\left(1-N_{t}^{k}\right) b^{k}+T_{t}^{k},
$$

implying that the government finances spending on unemployment benefits and net transfers by issuing bonds domestically.

\subsection{The foreign economy}

Since we treat the Euro Area as small economy, we model the RoW as a set of exogenous processes. The deviation of consumption from its' steady state follows an $\operatorname{AR}(1)$ process

$$
\left(\frac{C_{t}^{R o W}}{C^{R o W, S S}}\right)=\left(\frac{C_{t-1}^{R o W}}{C^{R o W, S S}}\right)^{\rho_{C} R o W} \epsilon_{t}^{C^{R o W}}
$$

where $\epsilon_{t}^{C^{R o W}}$ denotes a shock to foreign consumption and $0<\rho_{C^{R o W}}<1$. The allocation of consumption between Germany and the REA, however, will depend on the real exchange rate:

$$
\begin{aligned}
& C_{G E R, t}^{R o W}=n_{G E R}^{R o W}\left(\frac{P_{G E R, t}^{G E R}}{e_{R o W, t}^{G E R} P_{t}^{R o W}}\right)^{-\varpi} C_{t}^{R o W}, \\
& C_{R E A, t}^{R o W}=n_{R E A}^{R o W}\left(\frac{P_{R E A, t}^{R E A}}{e_{R o W, t}^{R E A} P_{t}^{R o W}}\right)^{-\varpi} C_{t}^{R o W} .
\end{aligned}
$$

Inflation is defined as $\pi_{t}^{R o W}=\frac{P_{t}^{R o W}}{P_{t-1}^{R o W}}$, which is also assumed to follow an $\operatorname{AR}(1)$ process with persistence $0<\rho_{\pi^{R o W}}<1$ :

$$
\left(\frac{\pi_{t}^{R o W}}{\pi^{R o W, S S}}\right)=\left(\frac{\pi_{t-1}^{R o W}}{\pi^{R o W, S S}}\right)^{\rho_{\pi} R o W} \epsilon_{t}^{\pi^{R o W}},
$$

where $\epsilon_{t}^{\pi^{R o W}}$ denotes an error term. We assume that the foreign monetary authority follows a Taylor rule: 


$$
\left(\frac{R_{t}^{R o W}}{R^{R o W, S S}}\right)=\left(\frac{R_{t-1}^{R o W}}{R^{R o W, S S}}\right)^{\tau_{r}}\left[\left(\frac{\pi_{t}^{R o W}}{\pi^{R o W, S S}}\right)^{\tau_{\pi}}\left(\frac{Y_{t}^{R o W}}{Y^{R o W, S S}}\right)^{\tau_{y}}\right]^{1-\tau_{r}} \epsilon_{t}^{R^{R o W}}
$$

where $\epsilon_{t}^{R o W}$ is a foreign monetary policy shock.

Finally, we assume that

$$
Y_{t}^{R o W}=C_{t}^{R o W}
$$

\subsection{The case of a currency union}

We now consider the currency union version of the model to account for the establishment of the EMU in 1999. We use this version to ensure that our sign restrictions to identify the wage moderation shocks hold under both a flexible exchange rate regime and a monetary union.

Our EMU model differs from the previous one in the way that the nominal exchange rate between GER and REA is normalized to 1 (i.e. all countries share the same currency) and that there is a single Euro Area central bank setting the nominal interest rate $R_{t}^{E A}$ according to the union wide inflation and output gap. The two regions are weighted according to the parameter $s=\frac{n_{G E R}^{G E R}}{n_{G E R}^{G E R}+n_{R E A}^{G E R}}$ :

$$
\begin{aligned}
\left(\frac{R_{t}^{E A}}{R^{E A, S S}}\right)= & \left(\frac{R_{t-1}^{E A}}{R^{E A, S S}}\right)^{\tau_{r}^{E A}}\left[\left(\frac{\pi_{t}^{G E R}}{\pi^{G E R, S S}}\right)^{s}\left(\frac{\pi_{t}^{R E A}}{\pi^{R E A, S S}}\right)^{1-s}\right)^{\tau_{\pi}^{E A}} \\
& \left.\left(\left(\frac{Y_{t}^{G E R}}{Y^{G E R, S S}}\right)^{s}\left(\frac{Y_{t}^{R E A}}{Y^{R E A, S S}}\right)^{1-s}\right)^{\tau_{y}^{E A}}\right]^{1-\tau_{r}^{E A}} \epsilon_{t}^{R^{E A}}
\end{aligned}
$$

However, the intra-regional interest rates are foreign debt elastic, meaning that interest rates across the region may differ according to their positions in net foreign assets. Consequently, as a net borrower (lender), the nominal interest rate rises (falls) above (below) the union wide nominal interest rate: 


$$
\begin{aligned}
R_{t}^{G E R} & =R_{t}^{E A} X_{E A, t}^{G E R}, \\
R_{t}^{R E A} & =R_{t}^{E A} X_{E A, t}^{R E A}, \\
R_{t}^{E A} & =R_{t}^{R o W} X_{R o W, t}^{E A} \frac{e_{t+1}}{e_{t}}
\end{aligned}
$$

with

$$
\begin{aligned}
X_{E A, t}^{G E R} & =e^{-\gamma\left(B_{t, F}^{G E R}-B_{F, t}^{R E A}\right)}, \\
X_{E A, t}^{R E A} & =e^{-\gamma\left(B_{t, F}^{R E A}-B_{F, t}^{G E R}\right)}, \\
X_{R o W, t}^{E A} & =e^{-\gamma\left(B_{t, F}^{G E R}+B_{F, t}^{R E A}\right)} .
\end{aligned}
$$

The German real exchange rates are then defined as:

$$
\begin{gathered}
\mathcal{Q}_{R E A, t}^{G E R}=\frac{P_{t}^{R E A}}{P_{t}^{G E R}} \\
\mathcal{Q}_{R o W, t}^{G E R}=\frac{e_{R o W, t}^{E A} P_{t}^{R o W}}{P_{t}^{G E R}}
\end{gathered}
$$

\subsection{Calibration and derivation of sign restrictions}

We follow the procedure outlined in Canova and Paustian (2011) to derive sign restrictions. The procedure seriously takes into account parameter uncertainty in order to derive responses whose signs can then be imposed as restrictions on the VAR. First, we define a reasonable space for each parameter. Second, we randomly draw from the parameter space 10,000 times and obtain impulse responses for each draw. We use a uniform distribution for the parameter space so we do not impose any strong prior about the value of parameters. Third, we collect the generated impulse responses and observe the signs as well as the periods over which the shocks produce positive or negative responses. This information then enables us to derive sign restrictions that are robust to parameter choice in terms of signs.

Table (1) shows the range of values considered for every parameter. The parameters $n$ are set in such a way that they cover a wide range of different weights. The discount factor $\beta$ is set to 0.99 , which corresponds to an annual interest rate of $4 \%$. The literature generally considers bargaining power parameters between 0.5 and 0.7 (see Weber (2000)). However, we also want to consider the case of 
lower bargaining power of households and let $\eta$ therefore vary between 0.3 and 0.7. The debt elasticity is fixed to 0.01 , which implies that an increase in the net foreign asset position by $10 \%$ translates into a decline in the borrowing rate by $0.1 \% .^{7}$ The degree of risk aversion ranges from 1 (log utility) to 2.5 , which corresponds to an elasticity of substitution in consumption of 0.4 . Hence, we consider a wide range of estimates by Vissing-Jorgensen (2002). The elasticity of labor supply ranges between 1 and 4, implying a Frisch elasticity between 0.25 and 1. These values are supported by Smets and Wouters (2007), Cho and Cooley (1994), and Chetty, Guren, Manoli, and Weber (2011). We allow the price stickiness parameter to vary between values used in Campolmi and Faia (2011) (20) and Krause, Lopez-Salido, and Lubik (2008) (100), which are in the lower and upper range of the literature. Moreover, the habit persistence coefficient takes values between 0.5 and 0.9 , which are common in the literature (for example see Smets and Wouters (2007)). With steady state matching efficiency parameter values between 0.5 and 0.9 , we cover the main range of estimates (see Pissarides and Petrongolo (2001) for a survey). Elasticities of demand between 5 and 8 imply mark-up ratios of prices over marginal costs between 1.14 and 1.25. This is in line with the estimates in Martins, Scarpetta, and Pilat (2003). We rely on vacancy costs between 0.05 and 0.15 (see for example Krause, Lopez-Salido, and Lubik (2008) and Yashiv (2000)). The parameter space for the separation rate is based on estimates by Hobijn and Sahin (2009). Pissarides and Petrongolo (2001) show that estimates for matching efficiency generally vary between 0.5 and 0.8. According to estimates for the vacancy duration by ECB (2002) and Weber (2000), we take the probability of finding a worker between 0.4 and 0.8 . With values for $v$ between 0.5 and 1 , we allow for constant and diminishing returns of labor. Additionally, we consider values between 1 and 3 for the elasticity of substitution between home and foreign goods, which is in line with estimates by Feenstra, Luck, Obstfeld, and Russ (2014). The ranges for the Taylor rule parameters relate to estimates by Orphanides $(2001) .^{8}$

For the autoregressive parameters of shocks, we set values between 0.5 and 0.9 for preference, labor supply, foreign output gap, and foreign inflation gaps. The technology shock is allowed to vary between 0.5 and 0.99 , i.e. an almost permanent shock on the upper bound. The two shocks of interest to us are the wage bargaining and matching efficiency shocks. Because reforms appear to have been permanent, at least for the observed sample period, these shocks could be thought of as non-stationary. However, bargaining power is bounded between 0 and 1. For this reason, we allow these shocks to be highly persistent with an

\footnotetext{
${ }^{7}$ Changing the debt elasticity only affects the persistence of the current account. Results, available on request, show that changing this parameter has no consequence for the identification of shocks.

${ }^{8} \mathrm{We}$ also vary the weights of countries in the consumption aggregator so that we allow for varying degrees of consumption home bias. This is done such that, on average, the REA is larger than Germany. The combination of parameters allows for home and foreign bias in consumption.
} 
Table 1: Parameter uncertainty

\begin{tabular}{|c|c|c|}
\hline Parameter & Name & Range \\
\hline$n_{G E R}^{G E R}$ & share of GER & {$[0.05,0.3]$} \\
\hline$n_{R E A}^{G E R}$ & share of REA & {$[0.3,0.69]$} \\
\hline$n_{R o W}^{G E R}$ & share of RoW & $1-n_{R E A}^{G E R}-n_{R o W}^{G E R}$ \\
\hline$\beta$ & discount factor & {$\left[1.04^{-0.25}\right]$} \\
\hline$\eta$ & bargaining power of households & {$[0.3,0.7]$} \\
\hline$\gamma$ & debt elasticity & 0.01 \\
\hline$\sigma$ & risk aversion & {$[1,2.5]$} \\
\hline$\varphi$ & elast. of labor supply & {$[1,4]$} \\
\hline$\psi$ & price stickiness & {$[20,100]$} \\
\hline$\omega$ & habits & {$[0.5,0.9]$} \\
\hline $\bar{m}$ & steady state matching efficiency & {$[0.5,0.9]$} \\
\hline$\epsilon$ & elast. of demand & {$[5,8]$} \\
\hline$\kappa$ & vacancy costs & {$[0.05,0.15]$} \\
\hline$\rho$ & separation rate & {$[0.05,0.1]$} \\
\hline$\nu$ & elasticity matching function & {$[0.5,0.8]$} \\
\hline$q\left(\theta_{t}\right)$ & probability of finding a worker & {$[0.4,0.8]$} \\
\hline$v$ & labor share & {$[0.5,1]$} \\
\hline$\mu$ & elast. of sub. between $(\mathrm{H})$ and $(\mathrm{F})$ goods & $(1,3]$ \\
\hline$\rho_{a}$ & technology shock (AR coef.) & {$[0.5,0.99]$} \\
\hline$\rho_{\eta}$ & bargaining power shock (AR coef.) & {$[0.5,0.99]$} \\
\hline$\rho_{m}$ & matching efficiency shock (AR coef.) & {$[0.5,0.99]$} \\
\hline$\rho_{P}$ & preference shock (AR coef.) & {$[0.5,0.9]$} \\
\hline$\rho_{L}$ & labor supply shock (AR coef.) & {$[0.5,0.9]$} \\
\hline$\rho_{c *}$ & foreign output gap (AR coef.) & {$[0.5,0.9]$} \\
\hline$\rho_{\pi *}$ & foreign inflation (AR coef.) & {$[0.5,0.9]$} \\
\hline$\tau_{r}$ & interest rate smoothing & {$[0.5,0.9]$} \\
\hline$\tau_{y}$ & output gap coef. & {$[0.1,0.5]$} \\
\hline$\tau_{\pi}$ & inflation coef. & {$[1.25,2.5]$} \\
\hline
\end{tabular}

autoregressive parameter of up to 0.99. For finite sample periods, the effect of permanent shocks would be equivalent. We carry out two experiments. In the first, we allow these parameters to vary between 0.5 and 0.99 . In the second, we fix these two shocks to have a persistence of $0.99 .^{9}$

Figures (2) to (5) display the $10 \%$ to $90 \%$ range of impulse responses for the 10,000 draws following a negative 1 SD shock to the bargaining power of households (i.e. a positive shock to the bargaining power of firms) as well as

\footnotetext{
${ }^{9}$ Reassuringly, fixing the persistence of the labor market shocks to 0.99 and the rest of the parameters to their mid-range, the simulated data for the current account in the model displayed an autoregressive persistence of 0.993 . Hence, the model is able to generate near non-stationary current account dynamics as those observed in the data.
} 
to the matching efficiency for both the pre-EMU and EMU model respectively. The figures correspond to the experiment where $\rho_{\eta}$ and $\rho_{m}$ vary between 0.5 and 0.99 . The rest of the impulse responses and those which correspond to the second experiment are reported in Appendix D.

Figure 2: Shock to bargaining power under parameter uncertainty (pre-EMU)
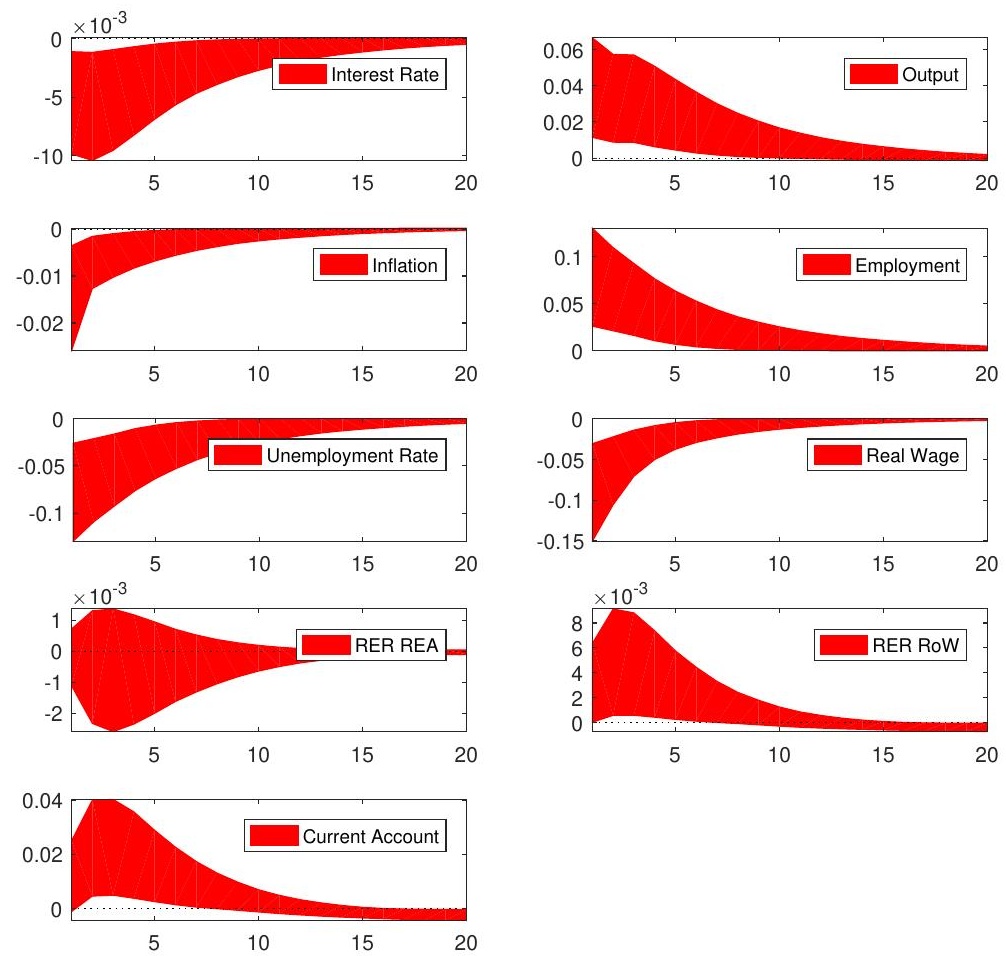

Note: $10 \%$ to $90 \%$ range of impulse responses for the 10,000 draws.

Overall, we find that the shocks to bargaining power lead to a decline in real wages and marginal costs, which translates into a lower inflation rate. Firms produce more output and demand more labor, which causes a decline in the unemployment rate. In the pre-EMU model, the nominal interest rate falls according to the Taylor rule, since more flexible labor markets reduce inflationary pressure. Matching efficiency shocks have similar effects on the dynamics of the endogenous variables, as they increase the probability of finding a match for firms and workers, reducing marginal costs. In the EMU model, because the central bank reacts to area-wide inflation, it reduces interest rates by less than in the pre-EMU model. The interest rate also falls because it is foreign debt elastic. The higher net foreign asset position reduces the debt elastic risk premium and thus the interest rate. Since UIP and LOP hold, the nominal exchange rate appreciates. The real exchange rate, however, can appreciate or depreciate de- 
Figure 3: Matching efficiency shock under parameter uncertainty (pre-EMU model)
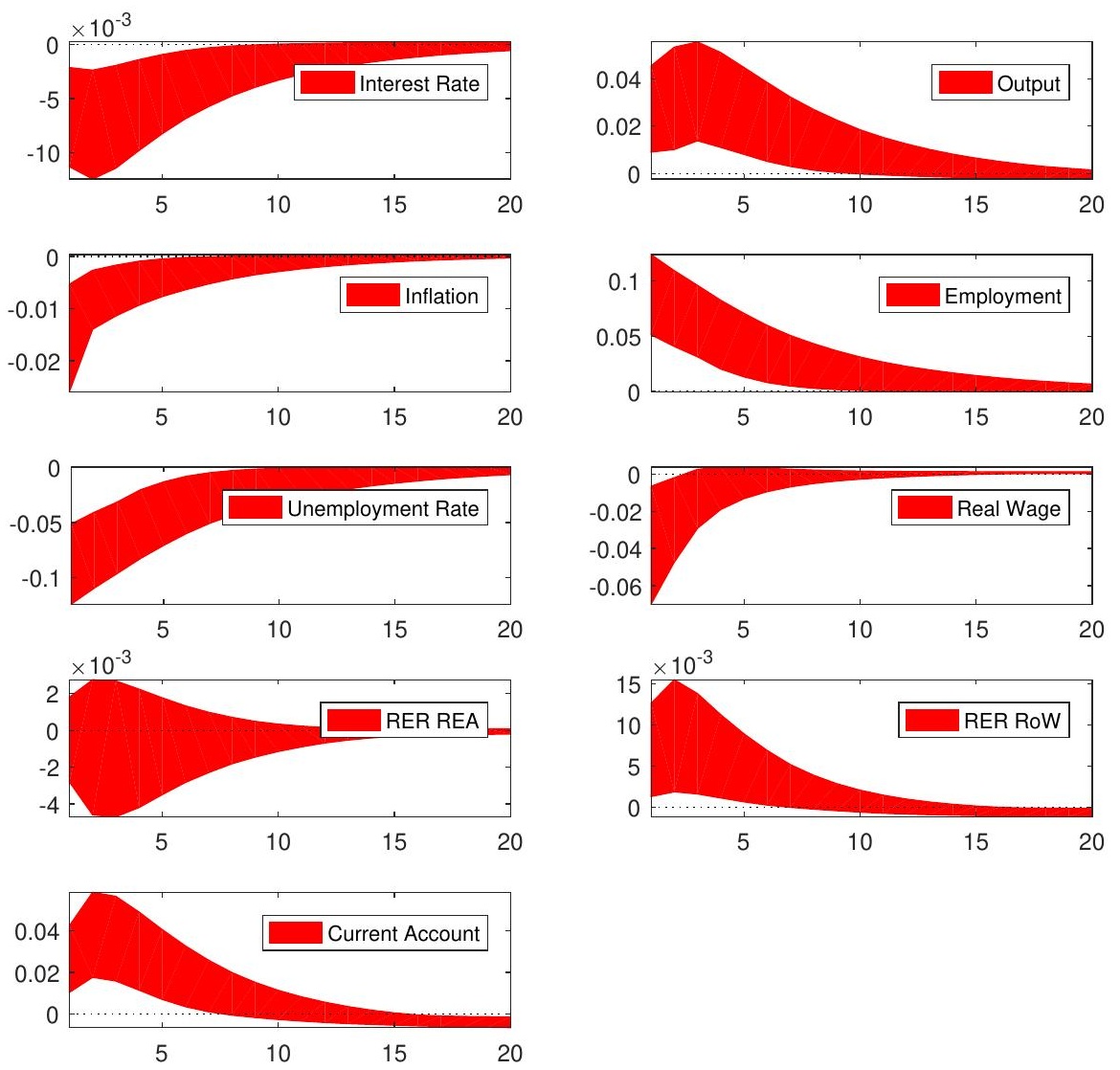

Note: The shaded area denotes the $10 \%$ to $90 \%$ range of impulse responses for the 10,000 draws.

pending on the home bias coefficient in consumption. With a high home bias, the fall in relative home prices leads to a depreciation of the real exchange rate. If home bias is low, because foreign prices have increased relative to home, the effect of the nominal exchange rate appreciation dominates. Results are similar if the autoregressive coefficients $\rho_{\eta}=\rho_{m}=0.99$ are fixed. The only exception is the response of output, which is negative on impact, but positive in the following quarters (see Figures (20) - (23) in Appendix D).

The robust responses obtained from the simulation of the model with parameter uncertainty then provide us with a method to identify shocks in the GVAR. This is a more agnostic way of identifying shocks than imposing the strong structure of a DSGE model on the data. The GVAR contains data on output $(y)$, 
Figure 4: Shock to bargaining power under parameter uncertaintv (EMU)
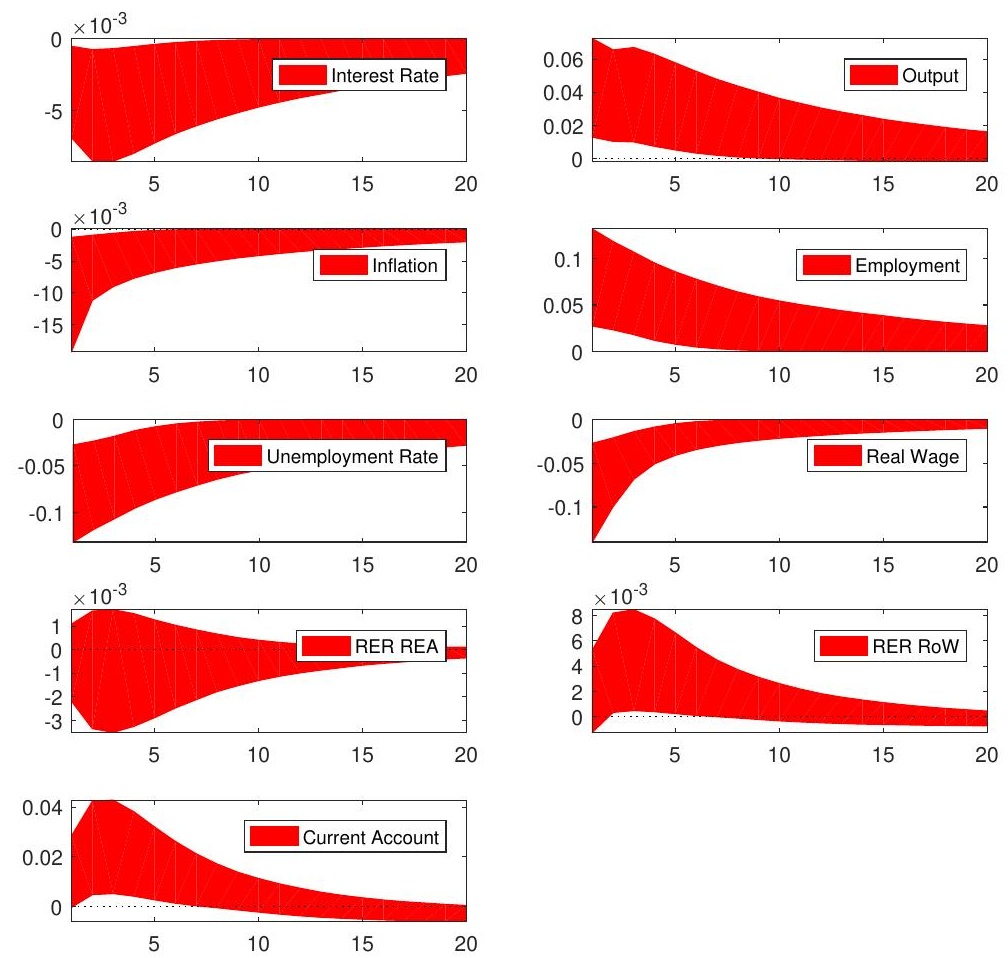

Note: $10 \%$ to $90 \%$ range of impulse responses for the 10,000 draws.

interest rates $(r)$, real wages $(w p)$, inflation $(D p)$, unemployment rate $(u)$, real exchange rate (reer), and the current account balance as a percentage of GDP $(c a)$. Thus, we look at the robust impulse-response signs obtained from the model for these variables. We do not, however, use restrictions on $c a$ since the reaction of this variable in the GVAR is our object of study and we do not want to restrict its behavior by assumption. We summarize the information in Tables (2) and (3). The tables show the signs of the impulse responses on impact for the pre-EMU and the EMU models. A "?" symbol denotes that the response is not robustly positive or negative, and framed values indicate the variables on which we imposed sign restrictions in the GVAR.

As shocks to bargaining power and matching efficiency yield responses which are qualitatively similar, we interpret a shock which simultaneously increases output and reduces real wages, inflation, and unemployment as a wage moderation shock. This is consistent with the pre-EMU the EMU models. Given that the response of output can be negative on impact if $\rho_{\eta}=\rho_{m}=0.99$ (see Figures 20 - 23), we impose a positive restriction on the response of output for the quarters 1-4 following the shock. Additionally, we impose restrictions on inflation inflation (-), real wages (-) and the unemployment rate over lags 0-4 on 
Figure 5: Matching efficiency shock under parameter uncertainty (EMU)
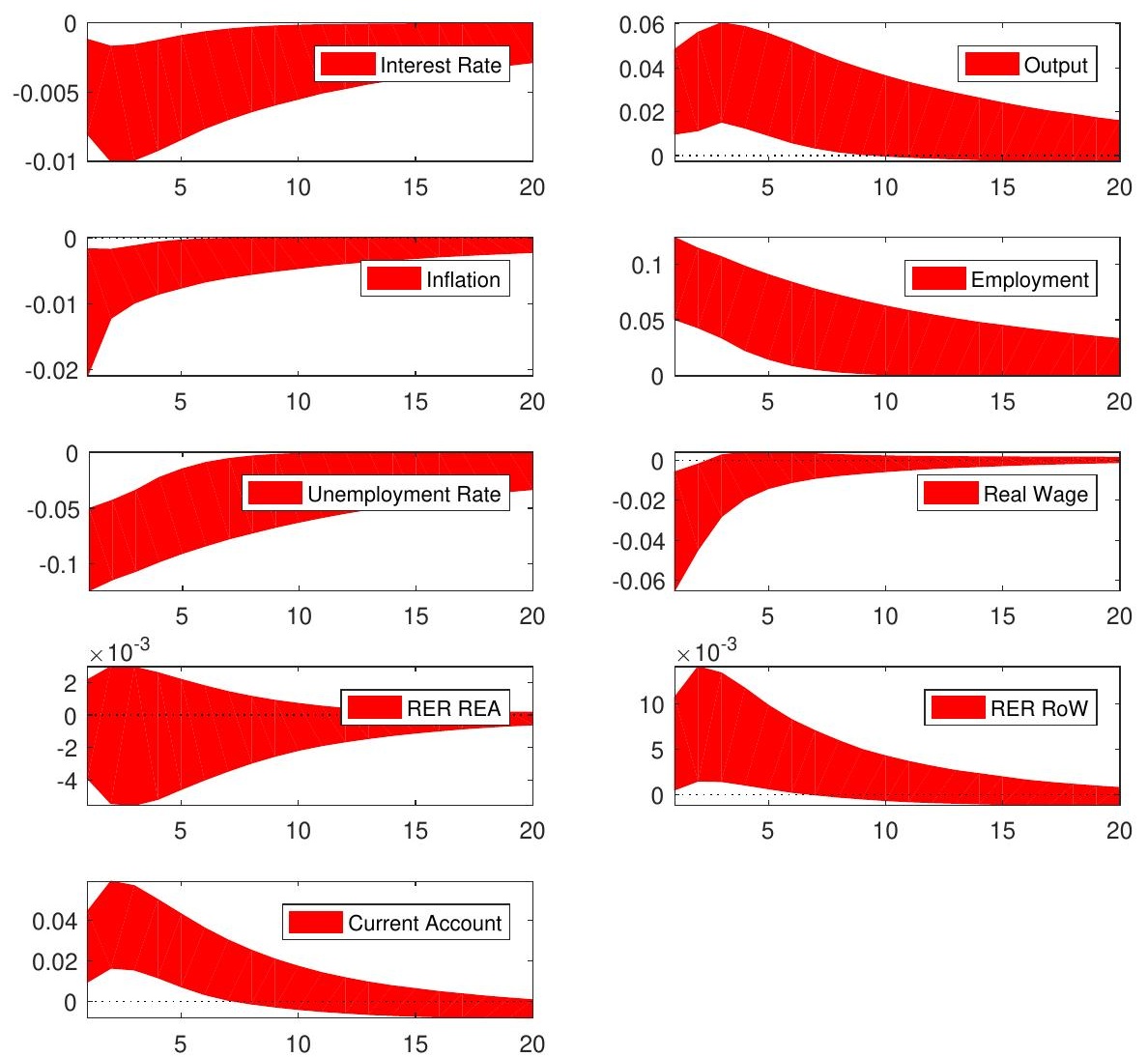

Note: The shaded area denotes the $10 \%$ to $90 \%$ range of impulse responses for the 10,000 draws.

the impulse response functions of the German model in the GVAR.

Given the fast reversion of inflation following the shock in the EMU model, we set the restriction on inflation only over the lags $0-1$. Specifically, all sign restrictions must satisfy the condition $>=0$ and $<=0$ (see Table 4 ).

\section{The GVAR model}

The GVAR model, introduced in the literature by Pesaran, Schuermann, and Weiner (2004), links country-specific VAR models using appropriate weights that allow tracing a country-specific shock into foreign economies. This is especially well suited to our purpose as we want to analyze the effect of a shock to the 
Table 2: Signs of the impact response intervals to different shocks (Pre EMU model)

\begin{tabular}{lccccccccc}
\hline & Y & $\mathrm{R}$ & $\mathrm{W}$ & $\mathcal{Q}$ & $\pi$ & $\mathrm{U}$ & $\mathrm{CA}$ \\
\hline Technology & + & - & - & $?$ & - & + & + \\
Bargaining power & + & & - & - & $?$ & - & - & $?$ \\
\cline { 2 - 6 } Matching efficiency & + & - & - & $?$ & - & - & + \\
\cline { 2 - 6 } Preference & $?$ & + & + & $?$ & + & - & - \\
Monetary policy & + & - & + & $?$ & + & - & + \\
Labor supply & + & - & - & $?$ & - & + & + \\
\hline
\end{tabular}

Note: The frames denote the restricted variables.

Table 3: Signs of the impact response intervals to different shocks (EMU model)

\begin{tabular}{lcccccccc}
\hline & $\mathrm{Y}$ & $\mathrm{R}$ & $\mathrm{W}$ & $\mathcal{Q}$ & $\pi$ & $\mathrm{U}$ & $\mathrm{CA}$ \\
\hline Technology & + & - & - & $?$ & \multicolumn{1}{c}{} & + & + \\
Bargaining power & + & - & - & $?$ & - & - & + \\
\cline { 2 - 6 } Matching efficiency & + & - & - & $?$ & - & - & + \\
\cline { 2 - 7 } Preference & $?$ & + & + & $?$ & + & - & - \\
Monetary policy & + & - & + & $?$ & + & - & + \\
Labor supply & + & - & - & $?$ & - & + & + \\
\hline
\end{tabular}

Note: The frames denote the restricted variables.

Table 4: Sign restrictions of wage moderation shock

\begin{tabular}{ccc}
\hline Variable & Sign & Horizon \\
\hline$y$ & $>=0$ & $1-4$ \\
$D p$ & $<=0$ & $0-1$ \\
$w p$ & $<=0$ & $0-4$ \\
$u$ & $<=0$ & $0-4$
\end{tabular}

Note: The table shows the theoretical sign restrictions, derived from the 3-region DSGE model. 
German labor market on the current account of other EMU members.

\subsection{Model set-up}

We estimate a GVAR model covering a set of 9 EMU countries using a sample of 61 observations ranging from 1992Q1 to 2007Q2. ${ }^{10}$ We consider the log levels of all variables involved (except for the current account and inflation). ${ }^{11}$

The variables entering the VAR for each economy $i=1, \ldots, 9$ are real GDP $(y)$, inflation rate $(D p)$, real wage $(r w)$, unemployment rate $(u)$, real effective exchange rate (reer), and the current account balance as ratio of GDP $(c a)$. The interest rate $(r)$ enters as an endogenous variable for Germany but exogenous for the rest of the countries. Table 5 presents the variable names and the corresponding data transformations. Note here that, for the empirical counterpart of the real exchange rate (reer), the definition is such that an increase corresponds to an appreciation. Details on data construction can be found in Appendix A.

Table 5: Variables entering the VAR and their transformations

\begin{tabular}{lll}
\hline Variable & Name & Transformation \\
\hline Real GDP & $y$ & $\ln \left(R G D P_{t}\right)$ \\
Inflation Rate & $D p$ & $\Delta \ln \left(C P I_{t}\right)$ \\
Real Wage & $w p$ & $\ln \left(\right.$ Compens. per empl./CPI $\left.I_{t}\right)$ \\
Unemployment Rate & $u$ & $\ln \left(\right.$ Unemployment Rate $\left.{ }_{t}.\right)$ \\
REER & reer & $\ln \left(R E E R_{t}\right)$ \\
Current Account Balance & $c a$ & $C A_{t} / N G D P_{t}$ \\
Interest Rate & $r$ & $0.25 * \ln \left(1+R_{t} / 100\right)$ \\
\hline
\end{tabular}

Table 6 presents detail about how different variables enter the model. Variables with a superscript ${ }^{*}$ are foreign trade-weighted variables as we will discuss below. Variables $x_{i t}$ represent the endogenous variables for each country model and $x_{i t}^{*}$ represent variables that enter exogenously. All variables, except the interest rate, are treated as endogenous in all country models. Since the German Mark served as anchor currency for the European Exchange Rate Mechanism (ERM), Germany plays the dominant role in our model. Thus, we employ the German interest rate as an endogenous variable in the German model, but as an

\footnotetext{
${ }^{10}$ The sample is chosen such that estimates are not subject to the potential biases arising from the German reunification or the 2008 financial crisis. The build up of the European imbalances occurred during this period. The financial crisis, however, led to the appearance of significant country-specific and global risk and partial current account re-balancing. This would require the consideration of a model that explicitly accounts for these factors and, thus, modelling the crisis period would be beyond the scope of this paper.

${ }^{11}$ For model estimation we use a modified version of the GVAR Toolbox by Smith and Galesi (2011).
} 
exogenous in all other country models. ${ }^{12}$ Note that the index " 2 " in the interest rate row refers to the second country in our model, which is Germany.

Table 6: Specification of the GVAR in terms of endogenous and exogenous variables

\begin{tabular}{|l|c|c|c|c|}
\hline \multirow{2}{*}{ Variables } & \multicolumn{2}{|c|}{ Germany } & \multicolumn{2}{c|}{ Others } \\
\cline { 2 - 5 } & $x_{i t}$ & $x_{i t}^{*}$ & $x_{i t}$ & $x_{i t}^{*}$ \\
\hline Real GDP & $y_{i t}$ & $y_{i t}^{*}$ & $y_{i t}$ & $y_{i t}^{*}$ \\
\hline Inflation Rate & $D p_{i t}$ & $D p_{i t}^{*}$ & $D p_{i t}$ & $D p_{i t}^{*}$ \\
\hline Real Wage & $r w_{i t}$ & $r w_{i t}^{*}$ & $r w_{i t}$ & $r w_{i t}^{*}$ \\
\hline Unemployment Rate & $u_{i t}$ & $u_{i t}^{*}$ & $u_{i t}$ & $u_{i t}^{*}$ \\
\hline Real Effective Exchange Rate & $r e e r_{i t}$ & - & $r e e r_{i t}$ & - \\
\hline Current Account Balance & $c a_{i t}$ & - & $c a_{i t}$ & - \\
\hline Interest Rate & $r_{2 t}$ & - & - & $r_{2 t}$ \\
\hline
\end{tabular}

Table 7: Trade Weight Matrix

\begin{tabular}{lrrrrrrrrr}
\hline Country & aut & deu & esp & fin & fra & gre & ita & nld & prt \\
\hline aut & 0.00 & 0.14 & 0.02 & 0.03 & 0.02 & 0.03 & 0.06 & 0.03 & 0.01 \\
deu & 0.68 & 0.00 & 0.27 & 0.45 & 0.40 & 0.31 & 0.37 & 0.55 & 0.22 \\
esp & 0.03 & 0.11 & 0.00 & 0.07 & 0.19 & 0.09 & 0.14 & 0.08 & 0.45 \\
fin & 0.01 & 0.03 & 0.01 & 0.00 & 0.01 & 0.02 & 0.01 & 0.03 & 0.01 \\
fra & 0.07 & 0.27 & 0.32 & 0.12 & 0.00 & 0.14 & 0.27 & 0.19 & 0.17 \\
gre & 0.01 & 0.02 & 0.01 & 0.01 & 0.01 & 0.00 & 0.03 & 0.01 & 0.00 \\
ita & 0.14 & 0.19 & 0.17 & 0.11 & 0.20 & 0.29 & 0.00 & 0.11 & 0.08 \\
nld & 0.05 & 0.22 & 0.08 & 0.19 & 0.12 & 0.11 & 0.10 & 0.00 & 0.07 \\
prt & 0.01 & 0.02 & 0.11 & 0.02 & 0.03 & 0.01 & 0.02 & 0.02 & 0.00 \\
\hline
\end{tabular}

We employ fixed trade weights (reported in Table 7) for the construction of foreign variables. ${ }^{13}$ The weights $\left(\omega_{i j}\right)$ represent the average total trade between country $i$ and $j$ relative to the total trade of country $i$ with all countries in

\footnotetext{
${ }^{12}$ We also tested a specification with a dominant unit as described by Chudik and Pesaran (2013). We let the interest rate be exogenous in all countries. In the single-equation dominant unit model the nominal interest rate is regressed on its own lag as well as lags of PPP-GDP weighted aggregates of output and inflation. This specification is similar to a mixed crosssection GVAR that models the ECB policy rule explicitly (see Georgiadis (2015)). The results were similar to those obtained from the benchmark model.

${ }^{13}$ We also estimated the model with two other alternative weight matrices derived from the IMF Coordinated Portfolio Investment Survey. We used the total portfolio investment asset positions of equity and debt instruments. As Eickmeier and Ng (2015), we reversed the direction of assignment by country in order to get matrices for outward and inward portfolio investment. The different weights (averages over the years 2004-2007) had only a very limited effect on our results. FDI and banking claims data are not available for our sample period.
} 
the sample over the years 1992 to 2007 . Foreign variables (except the nominal interest rate) are thus defined as:

$$
\begin{array}{ll}
y_{i t}^{*}=\sum_{j=1}^{N} \omega_{i j} y_{j t} & D p_{i t}^{*}=\sum_{j=1}^{N} \omega_{i j} D p_{j t} \\
u_{i t}^{*}=\sum_{j=1}^{N} \omega_{i j} u_{j t} & r w_{i t}^{*}=\sum_{j=1}^{N} \omega_{i j} r w_{j t}
\end{array}
$$

We now describe the specification and identification method used for the GVAR estimates.

\subsection{The single-country models}

Due to the small sample size, each economy $i$ is represented by the $\operatorname{VARX}^{*}(1,1)$ model

$$
x_{i t}=a_{i 0}+a_{i 1} t+\Phi_{i 1} x_{i, t-1}+\Lambda_{i 0} x_{i t}^{*}+\Lambda_{i 1} x_{i, t-1}^{*}+u_{i t},
$$

where $x_{i t}$ denotes the vector of domestic variables and $x_{i t}^{*}$ the vector of foreign exogenous variables. $a_{i 0}$ and $a_{i 1}$ are column vectors of $k_{i} \times 1$ dimension denoting coefficients of constants and time trends, respectively. The coefficient matricies $\Phi_{i l}$ and $\Lambda_{i l}$ are of $k_{i} \times k_{i}$ dimension. $u_{i t}$ is a $k_{i} \times 1$ vector and assumed to be IID with zero mean and covariance matrix $\Sigma_{i i}$.

After further transformations, we get

$$
A_{i 0} z_{i t}=a_{i 0}+a_{i 1} t+A_{i 1} z_{i t-1}+u_{i t}
$$

where

$$
z_{i t}=\left(x_{i t}, x_{i t}^{*}\right)^{\prime}, \quad A_{i 0}=\left(I_{k_{i}},-\Lambda_{i 0}\right), \quad A_{i 1}=\left(\Phi_{i 1}, \Lambda_{i 1}\right) .
$$

In order to solve the GVAR, we define the vector $z_{i t}$ in terms of the global vector $x_{t}=\left(x_{0 t}^{\prime}, x_{1 t}^{\prime}, \ldots, x_{9 t}^{\prime}\right)$ as

$$
z_{i t}=W_{i} x_{t}
$$

where $W_{i}$ denotes a weight matrix. It follows that

$$
A_{i 0} W_{i} x_{t}=a_{i 0}+a_{i 1} t+A_{i 1} W_{i} x_{t-1}+u_{t}
$$


By stacking all models, we obtain

$$
G_{0} x_{t}=b_{0}+b_{1} t+G_{1} x_{t-1}+c_{t}
$$

where

$$
b_{0}=\left(\begin{array}{c}
a_{00} \\
a_{10} \\
\vdots \\
a_{N 0}
\end{array}\right), \quad b_{1}=\left(\begin{array}{c}
a_{01} \\
a_{11} \\
\vdots \\
a_{N 1}
\end{array}\right), \quad c_{t}=\left(\begin{array}{c}
u_{0 t} \\
u_{1 t} \\
\vdots \\
u_{N t}
\end{array}\right)
$$

and

$$
G_{0}=\left(\begin{array}{c}
A_{00} W_{0} \\
A_{10} W_{1} \\
\vdots \\
A_{N 0} W_{N}
\end{array}\right), \quad G_{1}=\left(\begin{array}{c}
A_{01} W_{0} \\
A_{11} W_{1} \\
\vdots \\
A_{N 1} W_{N}
\end{array}\right)
$$

Premultiplying $(72)$ by $G_{0}$ yields

$$
x_{t}=f_{0}+f_{1}+F_{1} x_{t-1}+\epsilon_{t}
$$

where

$$
f_{0}=G_{0}^{-1} b_{0}, f_{1}=G_{0}^{-1} b_{1}, F_{1}=G_{0}^{-1} G_{1}, \epsilon_{t}=G_{0}^{-1} c_{t}
$$

The final equation (73) represents our GVAR model, which we obtain from the estimated single country models.

\subsection{Shock identification}

We apply our agnostic sign restriction approach, as proposed by Eickmeier and $\mathrm{Ng}$ (2015), in order to identify the wage moderation shock in Germany. ${ }^{14}$ The advantage of this procedure is that identified shocks are not correlated within countries and only weakly correlated across countries. This enables us to interpret a particular shock as country-specific.

We impose sign restrictions using the algorithms outlined in Rubio-Ramirez,

\footnotetext{
${ }^{14}$ The literature on sign restrictions was initiated by Faust (1998), Canova and Nicolo (2002) and Uhlig (2005).
} 
Waggoner, and Zha (2011) and Fry and Pagan (2007). Given the residuals from each estimated country $i$ model, we compute lower triangular Cholesky matrices $P_{i}$ and create a matrix

$$
P=\left(\begin{array}{ccccc}
P_{0} & 0 & \ldots & \ldots & 0 \\
0 & \ddots & & & \vdots \\
\vdots & & P_{i} & & \vdots \\
\vdots & & & \ddots & 0 \\
0 & \ldots & \ldots & 0 & P_{N}
\end{array}\right)
$$

which gives us the impulse responses $\psi^{h}=\phi^{h} G_{0}^{-1} P$, where $\phi^{h}$ denotes the $h^{\text {th }}$ matrix of the vector moving average representation of the GVAR having a $K \times$ $K$ dimension. We draw random $k_{2} \times k_{2}$ orthonormal matrices ${ }^{15}$ and perform QR-decompositions, which provide unique matrices $\left(Q_{2}\right)$ that satisfy $Q_{2} Q_{2}^{\prime}=$ $I$. We rotate $Q_{2}$ in order to obtain 1,000 impulse responses (given by $\Psi_{i}^{h}=$ $\left.\left(\psi_{i}^{h} Q_{i}^{\prime}\right)^{\prime}\right)$, which satisfy our sign restrictions. Since inflation reverts faster than other variables, we impose the restriction on inflation only over the quarters 0-1. The restriction for output, as discussed above, holds for periods 1 to 4, whereas other restrictions must hold for quarters $0-4$. Since we identify only one shock in a country with 7 variables, we also impose restrictions on the other variables to ensure that the identified shock only appears in the first equation. This strategy enables us to circumvent the multiple shocks problem discussed by Fry and Pagan (2007). The design of the P matrix, however, requires the assumption that there is no correlation between the shocks across countries. Within the GVAR, this is accounted for by matrix $G_{0}$, which captures the contemporaneous spillovers across countries.

The 1,000 draws obtained produce impulse responses which satisfy our sign restrictions according to Tables 2 and 3. However, not all draws are necessarily related to the same data generating process (DGP). Reporting measures like certain percentiles from the distribution of these impulse responses as confidence bands may thus be a malpractice (see Fry and Pagan (2007)). Following Fry and Pagan (2007), we deal with the multiple model problem by selecting the model which produces the impulse responses having the smallest total deviation from the medians of all impulse responses. In the case of the GVAR, we only take German variables into account, because we are focusing on a country-specific shock. The rest of our analysis proceeds by discussing the bootstrap (of 1,000 draws) of this median target model. We are thus able to identify a countryspecific shock in Germany and the GVAR model enables us to trace this shock into foreign countries and to quantify its effect on foreign variables.

\footnotetext{
${ }^{15}$ The index 2 refers to country 2 , which is Germany $\left(k_{2}=7\right)$.
} 


\section{Results}

We now discuss the impulse responses following a wage moderation shock in Germany and analyze the importance of the shock as a driver of current account balances by decomposing its forecast error variance. As discussed earlier, the model generates stationary but highly persistent current account dynamics. Although for the finite sample period we have in the data this is observationally equivalent to non-stationarity, the current account cannot be asymptotically non-stationary. Therefore, we should expect that a wage moderation shock in Germany led to highly persistent but stationary effects on EMU current accounts. This is why, along the same lines as Kollmann, Ratto, Roeger, in't Veld, and Vogel (2015), we proceed by considering a shock with transitory but potentially highly persistent effects on the current account.

\subsection{A German wage moderation shock}

In Figure (6), we report the German impulse responses following a 1 standard deviation wage moderation shock. The light blue area represents the $90 \%$ confidence bands, the dark blue area the $68 \%$ confidence bands and the red line the median. Following a negative one standard deviation wage moderation shock, real wages, inflation and the unemployment rate fall by definition, while output improves. It is noticeable that the shock generates a very persistent response of the current account. The median response takes about 40 quarters to settle back to equilibrium. Output, the real exchange rate, and unemployment also display highly persistent responses.

We find that the interest rate increases slightly by approximately $0.01 \%$. This results from the large and persistent output increase following the shock while inflation falls only by a small amount and quickly returns to equilibrium within a quarter. The real effective exchange rate appreciates by $0.4 \%$. The appreciation following a supply shock is a common finding in the literature and often referred to as perverse supply side effect. Farrant and Peersman (2006), for example, find this effect for the Euro Area. Note, however, that this response is not inconsistent with the model, which can generate both positive and negative responses. Importantly, and in line with the DSGE model, we find a very significant improvement of the German current account balance by about $0.13 \%$.

Following Canova and Paustian (2011), we analyze the difference between the impulse responses derived directly from the rotation matrices and the Fry and Pagan (2007) median target model. We report all the impulse responses computed using the 1,000 accepted rotation matrices in Figure 7. The impulse response functions of the Fry and Pagan (2007) median target model are colored red. The Figure indicates that the difference between both approaches is very small. However, a comparison of both procedures is difficult, because they mea- 
Figure 6: Impulse responses of a German wage moderation shock on German variables (in \%). The light blue area represents the $90 \%$ confidence bands, the dark blue area the $68 \%$ confidence bands, and the red line the median.
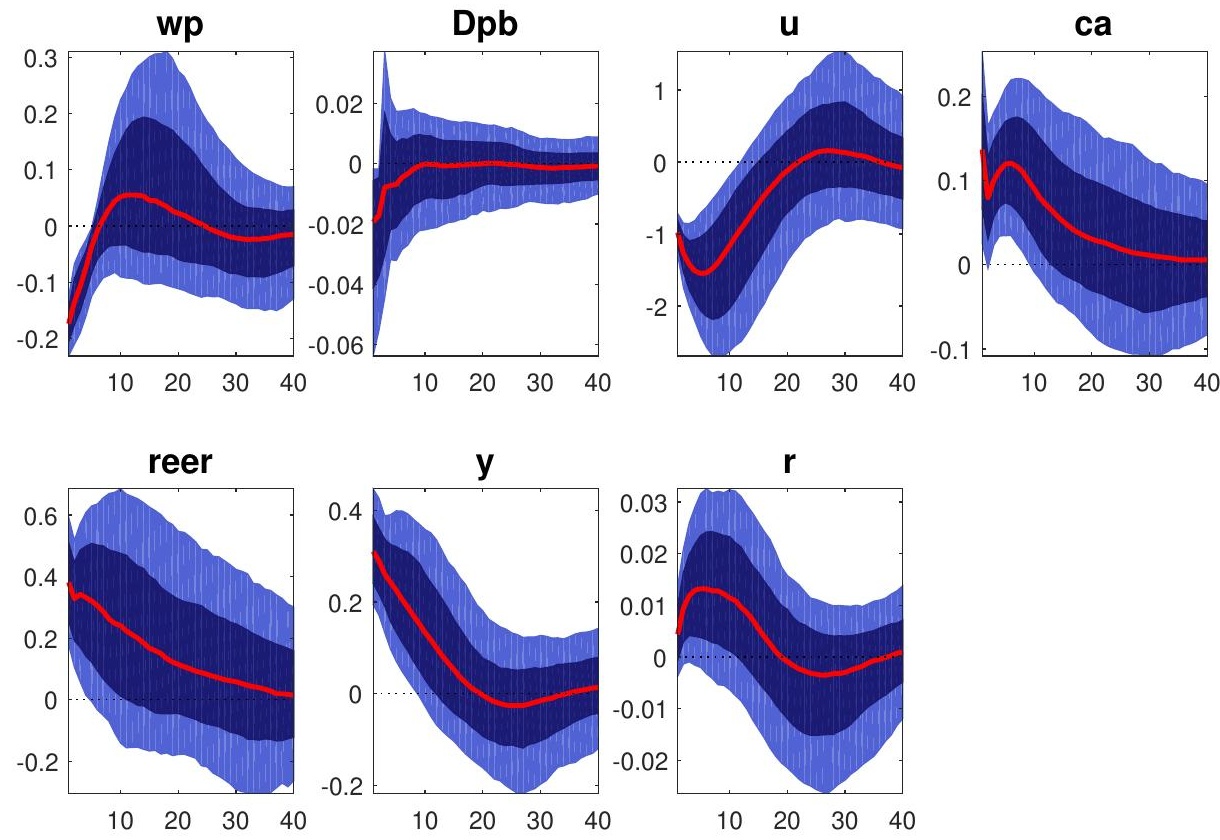

sure very different objects. The distribution of impulse responses derived from the rotation matrices is closer to a measure of model uncertainty. The Fry and Pagan (2007) approach, on the other hand, is a measure of estimation uncertainty as it involves a bootstrap (re-sampling of residuals) of the target model. We observe that the results for the REER and the interest rate vary, meaning that the results of the median target model may not necessarily be significant when considering all possible models. However, the current account response is robustly positive after two quarters.

We now look at the response of the current accounts of the other countries following the German labor market shock. Figure 8 shows that the response of other European current account balances is very heterogeneous. We report the corresponding $90 \%$ as well as $68 \%$ error bands in Figure 9. The Figure unveils significant deteriorations in Greece and the Netherlands, but significantly positive responses in Spain, Finland and France. The responses of the Austrian, Italian and Portuguese current accounts are insignificant. 
Figure 7: Impulse responses to a wage moderation shock for the 1,000 accepted rotation matrices for Germany (in \%). Fry and Pagan (2007) median target responses are colored red.
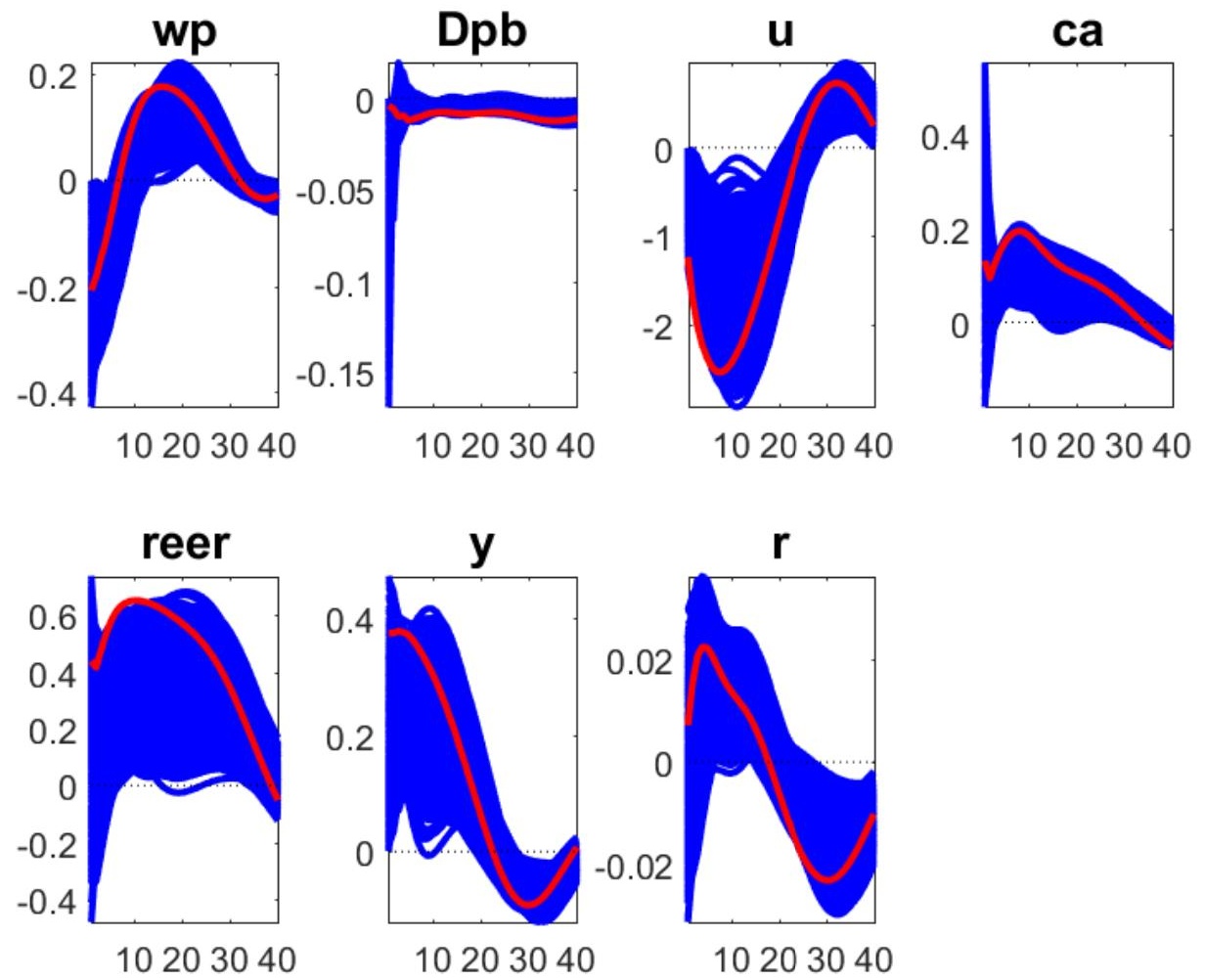

\subsection{Forecast Error Variance Decomposition}

We now present the forecast error variances (FEV) of European current account balances explained by German wage moderation shocks. This measures the importance of these shocks to explain the variability of current accounts. As stated earlier, German shocks are orthogonal, whereas foreign shocks are weakly correlated. Therefore, we rely on Generalized FEV decompositions and focus on the ranking of explained shares. ${ }^{16}$

Table 8 presents the FEV decomposition for the wage moderation shock using the median target model and for different horizons. Not surprisingly, the German shock explains more of the domestic current account balance forecast error variance on impact. For the other EMU countries, only for France and Italy we

\footnotetext{
${ }^{16}$ With sign restrictions, it is important that the restricted shock contributes substantially to explain the forecast error variance of the variables entering the VAR. This is the case in our GVAR. On impact, the wage moderation shock explains, for instance, $35 \%, 14 \%$ and $18 \%$ of the forecast error variance of German unemployment, real exchange rate, and output respectively. These contributions increase for the 1 year FEV horizon.
} 
Figure 8: Median responses of European current account balances to a German wage moderation shock (in \%)

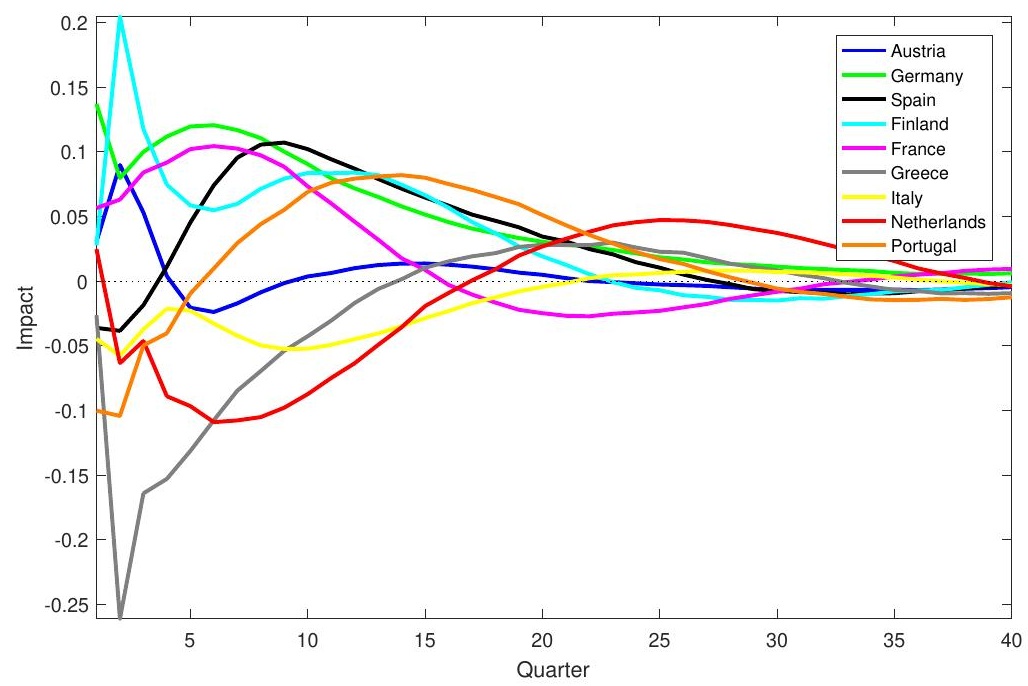

Figure 9: Confidence intervals for European current account balances (in \%)
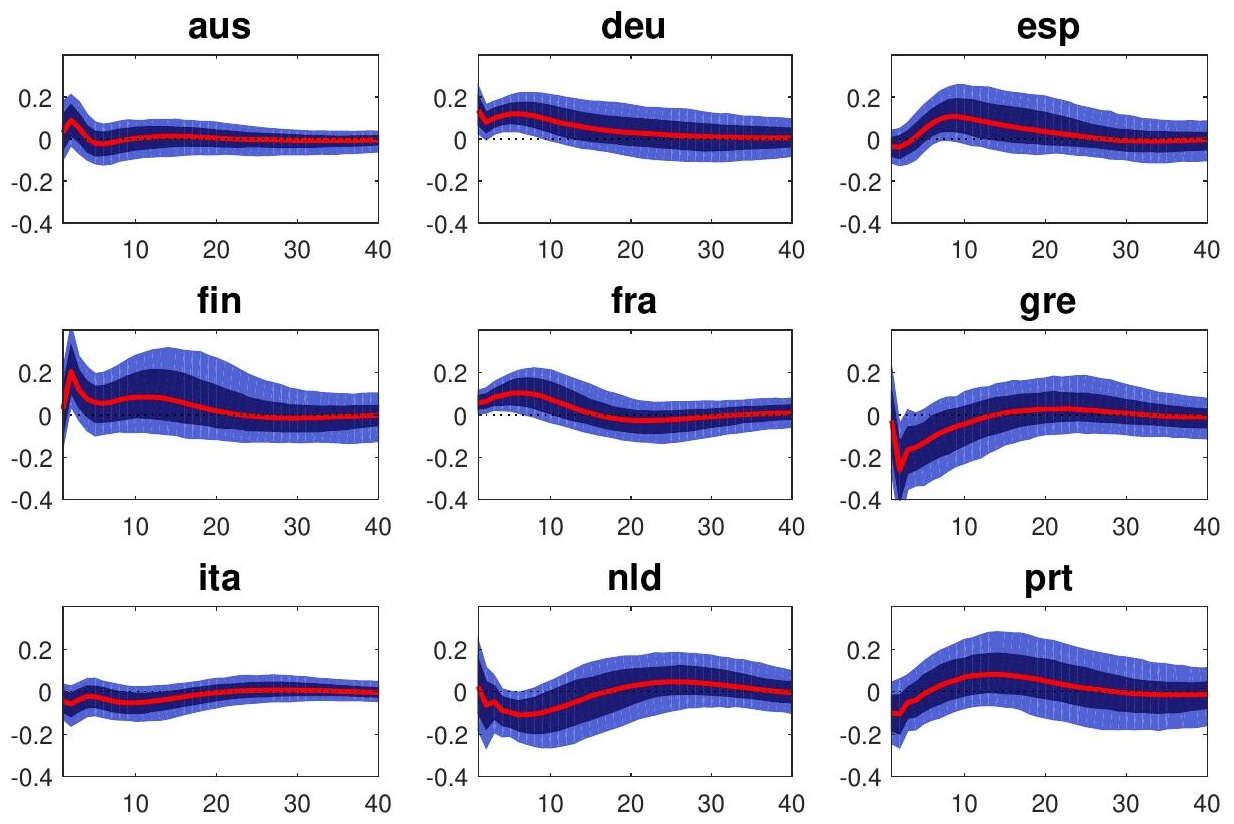

observe a relatively important effect of these shocks but only after 5 years. The general picture, however, is that the German wage moderation shock explains a much smaller fraction of the forecast error of the current account for other EMU 
Table 8: Forecast error variance of current account balances explained by a German wage moderation shock

\begin{tabular}{l|rrr}
\hline Country & Impact & Year 1 & Year 5 \\
\hline aut & 0.01 & 0.03 & 0.05 \\
deu & 0.06 & 0.12 & 0.13 \\
esp & 0.01 & 0.02 & 0.08 \\
fin & 0.01 & 0.04 & 0.06 \\
fra & 0.02 & 0.08 & 0.11 \\
gre & 0.00 & 0.04 & 0.05 \\
ita & 0.01 & 0.03 & 0.06 \\
nld & 0.01 & 0.02 & 0.05 \\
prt & 0.01 & 0.02 & 0.05 \\
\hline
\end{tabular}

countries indicating that the shock is not a very important driver of European current account balances.

\section{Counterfactual analysis}

The next step in our analysis is to quantify the contribution of the German labor market shock to the levels of both the German and other EMU countries' current accounts. To do so, we perform a counterfactual analysis where we set the German wage moderation innovations to zero. As the GVAR methodology explicitly allows for international linkages, we are able to trace the effects of changing the errors of domestic or foreign equations on the evolution of specific variables. This can be achieved by choosing a specific base point $(B)$ in our sample from which we forecast $B+1, B+2, \ldots, B+h$ conditional on the information available until $(B)$. It is important to note that $B+h$ is part of the sample.

By adding the contributions of all (known) future shocks to the forecast for every point in time $(B+1, B+2, \ldots, B+h)$, we automatically recreate the dataset. However, if we assume that the errors of a specific equation $(j)$ are zero and remove their contribution from the base projection for every point in time, we obtain a counterfactual time series showing what would have happened if that specific shock is canceled out.

This method is best explained using the following notation

$$
y_{B+h}=\sum_{i=0}^{h-1} \phi_{i} \epsilon_{B+h-i}+\phi_{h} y_{B}
$$

where $\phi_{i}$ denotes the $i$-th moving average parameter as shown by Lütkepohl (2005). 
Plugging the manipulated innovations back to the model provides us with new data representing a world without German wage moderation shocks. For this exercise, we use the model corresponding to the Fry and Pagan (2007) median target. To derive the counterfactual current account balance, we proceed as follows. To obtain a dataset excluding negative German bargaining power shocks from time $B$ onwards, we keep the (known) future errors of all equations and set the (structural) wage moderation shocks in $\epsilon_{t}$ to zero. Then we perform a h-step ahead forecast starting at time $B$ for all $k$ endogenous variables in our system. Finally, we compute the contributions of the known errors for every observation from $B$ to $B+h$ and add them to the base projection. Given the actual data and the counterfactual series, we may draw conclusions about the historical importance of the bargaining power shock.

Figure 10: Original and counterfactual data of the German CA/GDP ratio (1992Q3-2007Q2, in \%)

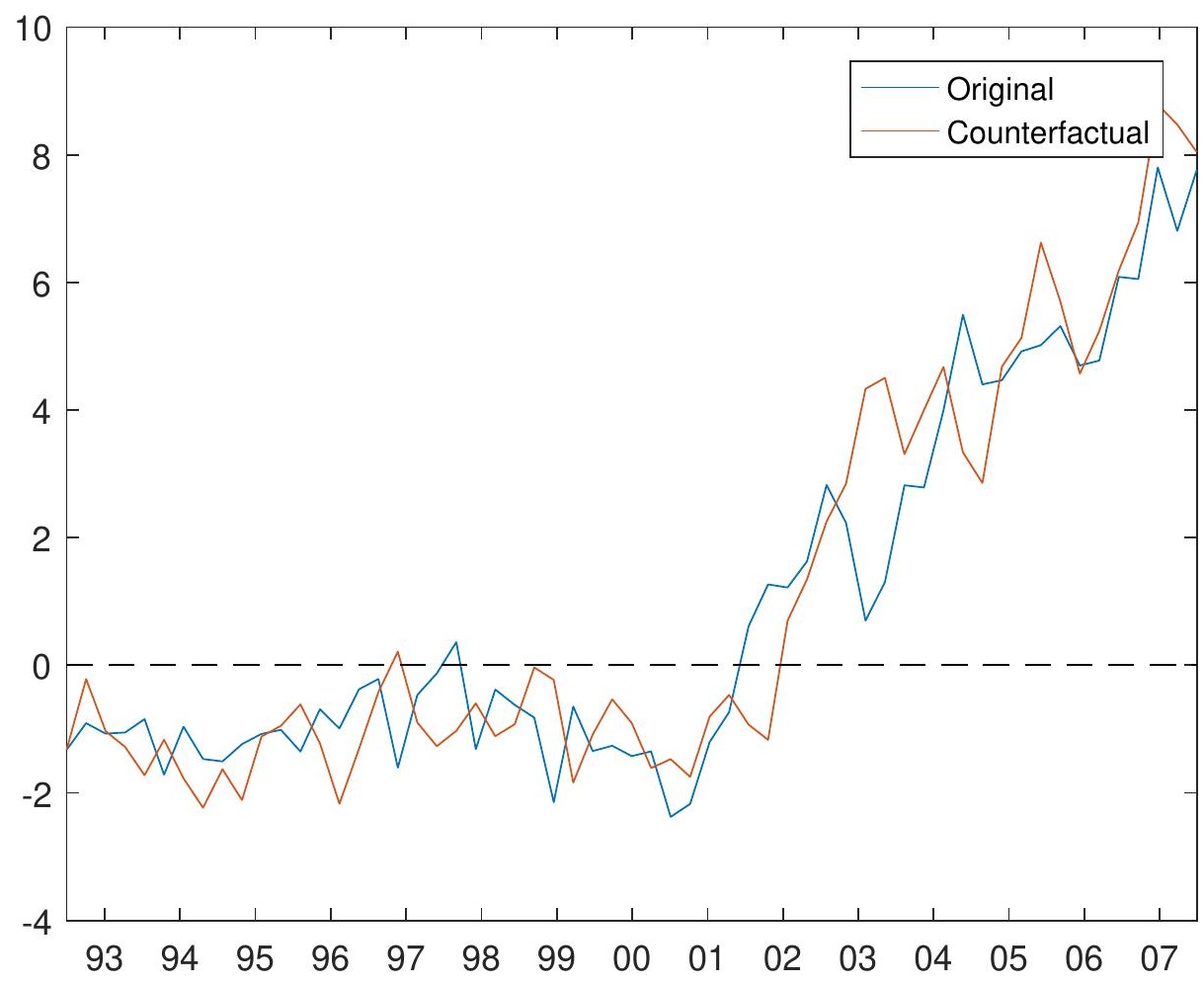

Figure 10 displays both, the original data and the counterfactual data of the German current account as ratio of GDP. We observe that both series move very close to each other. Only during the early and mid-2000s, the German current account balance would have been lower, if wage moderation shocks were absent. But during 2003 and 2004 the current account balance would have actually been 
higher. In general, the effect of the shock on the current account balance is very small.

We also compute the contribution of the shock to the dispersion of current account balances for all the countries. We calculate the sum of the absolute deviation $\left(A D_{t}\right)$ of current account to GDP ratios as a measure of dispersion:

$$
A D_{t}=\sum_{i=1}^{N}\left|c a_{i t}\right|,
$$

for $i=1, \ldots, N$ and $N=9$. We then compute $A D_{t}$ for the counterfactual current account series setting the German wage moderation shocks to zero and compare both series.

Figure 11: Original and counterfactual dispersion of all CA/GDP ratios (1992Q32007Q2, in \%)

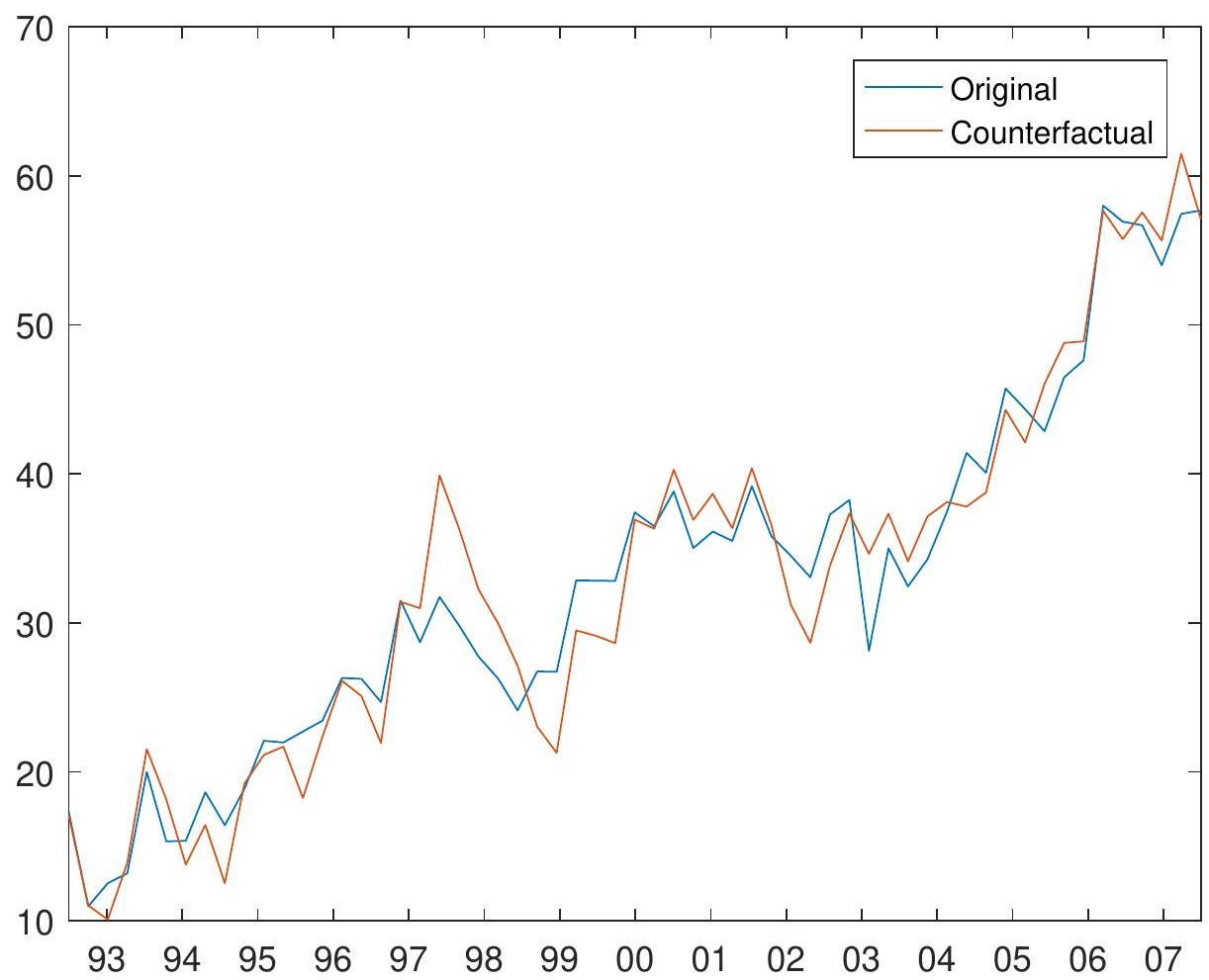

Figure 11 shows that the absolute deviation increases substantially over the whole sample period, which is a measure of the well known increase in European external imbalances. While the total absolute deviation of current account to GDP ratios was only approximately $10 \%$ in 1993, it reached almost $60 \%$ in 
2006. The difference between the original and counterfactual series, however, indicates that the identified German wage moderation shocks play a very minor role for European Imbalances. The maximum difference between the original and counterfactual series is approximately $3.2 \%$ in 2002. Between the years 2000 and 2003 and 2005 and 2007, the divergence would have been slightly lower without these shocks. However, this difference is quantitatively small.

\section{Conclusion}

A popular explanation of the increase in the dispersion of current account positions in the Eurozone states that they originate from gains in German competitiveness resulting from labor market reforms during the late 1990s and early 2000s. Two crucial elements of these reforms were the reduction in wage setting bargaining power of unions (and union coverage) and an increase in the efficiency of labor market matching, which we label jointly as "wage moderation" policies. We analyze quantitatively the effect of shocks to wage moderation in Germany on the current account positions of 9 Eurozone countries.

We develop a 3-country open economy New Keynesian DSGE model of Germany, the rest of the Euro Area (REA), and the rest of the World. The model displays search and matching frictions for Germany and the REA and shocks to matching efficiency and wage bargaining power of workers. From the model, we derive sign restrictions to identify a wage moderation shock. The shock robustly reduces wages, inflation, and unemployment and increases output. We then impose these sign restrictions to identify German wage moderation shocks in a Global VAR (GVAR) including Germany and 8 other EMU countries. The GVAR allows us to trace the shock spillovers originating in Germany on the rest of the countries within the system. This method is more model-agnostic and imposes less structure on the data than estimated DSGE models.

The results from the estimated GVAR show that German wage moderation shocks were important drivers of output, unemployment, wages, and the current account in Germany. After a shock that either reduces the bargaining power of unions or increases matching efficiency, the German current account improves significantly. However, the effect of the shock on other European economies is very small. Responses to the shock are generally heterogeneous and the importance of the shock to explain the variance of current account positions in EMU countries is very limited. Counterfactual analysis indicates that, had these shocks been absent, the dispersion of current account positions would have looked very similar to what it was. Consequently, the wage moderation resulting from the German labor market reforms cannot be the lone driver of European current account imbalances. 


\section{References}

Boots, J. C. G., W. Feibes, and J. H. C. Lisman (1967): "Further methods of derivation of quarterly figures from annual data," Journal of the Royal Statistical Society. Series C (Applied Statistics), 16(1), 65-75.

Bundesbank (2011): “Monthly Report," October 2011.

Busl, C., And A. Seymen (2013): "The German labour market reforms in a European context: A DSGE analysis," ZEW Discussion Papers, (13-097).

Campolmi, A., And E. FAiA (2011): "Labor market institutions and inflation volatility in the euro area," Journal of Economic Dynamics and Control, 35(5), 793-812.

Canova, F., and G. D. Nicolo (2002): "Monetary disturbances matter for business fluctuations in the G-7," Journal of Monetary Economics, 49(6), $1131-1159$.

Canova, F., and M. Paustian (2011): " Measurement with Some Theory: a New Approach to Evaluate Business Cycle Models (with appendices)," Barcelona Graduate School of Economics Working papers, (511).

Chen, R., G.-M. Milesi-Ferretti, And T. Tressel (2012): "External imbalances in the euro area," IMF Working Paper, 12/236.

Chetty, R., A. Guren, D. Manoli, and A. Weber (2011): "Are Micro and Macro Labor Supply Elasticities Consistent? A Review of Evidence on the Intensive and Extensive Margins," American Economic Review, 101(3), $471-475$.

Cho, J.-O., And T. Cooley (1994): "Employment and Hours over the Business Cycle," Journal of Economic Dynamics and Control, 18(2), 411-432.

Chudik, A., and H. Pesaran (2013): "Econometric Analysis of High Dimensional VARs Featuring a Dominant Unit," Econometric Reviews, 32(5-6), 592-649.

ECB (2002): "Labour market mismatches in the euro area countries," European Central Bank.

Eichorst, W., And P. Marx (2009): "Reforming German Labor Market Institutions: A Dual Path to Flexibility," IZA Discussion Paper, (4100).

EickmeieR, S., AND T. NG (2015): "How do credit supply shocks propagate internationally? A GVAR approach," European Economic Review, (74), 128145. 
Fahr, R., And U. Sunde (2009): "Did the Hartz Reforms Speed-Up the Matching Process? A Macro-Evaluation Using Empirical Matching Functions," German Economic Review, 10(3), 284-316.

Farrant, K., and G. Peersman (2006): "Is the Exchange Rate a Shock Absorber or a Source of Shocks? New Empirical Evidence," Journal of Money, Credit, and Banking, 38(4), 939-961.

FAust, J. (1998): "The Robustness of Identified VAR Conclusions about Money," Carnegie-Rochester Series on Public Policy, 49, 207-244.

Feenstra, R. C., P. A. Luck, M. Obstfeld, and K. N. Russ (2014): "In Search of the Armington Elasticity," NBER Working paper Series, (20063).

Fry, R., And A. Pagan (2007): "Some Issues in Using Sign Restrictions for Identifying Structural VARs," NCER Working Paper Series 14, National Centre for Econometric Research.

Gadatsch, N., K. Hauzenberger, and N. Stähler (2016): "Fiscal policy during the crisis: A look on Germany and the Euro area with GEAR," Economic Modelling, 52(PB), 997 - 1016.

Gadatsch, N., N. StähleR, and B. Weigert (2014): "German labor market and fiscal reforms 1999 to 2008: Can they be blamed for intra-Euro Area imbalances?," .

Georgiadis, G. (2015): "Examining asymmetries in the transmission of monetary policy in the euro area: Evidence from a mixed cross-section global VAR model," European Economic Review, 75(0), 195 - 215.

Hobijn, B., And A. SAhin (2009): "Job-finding and separation rates in the OECD," Economics Letters, 104(3), 107-111.

Hobza, A., And S. Zeugner (2014): "The "imbalanced balance" and its unravelling: current accounts and bilateral financial flows in the euro area," Economic Papers, European Commission, 520.

ILO (2012): "Global Employment Trends 2012," .

IMF (2012): "IMF - Group of Twenty, Umbrella Report," .

Ivanova, A. (2012): "Current Account Imbalances: Can Structural Policies Make a Difference?," IMF Working Paper, (12/61).

Jacob, P., and G. Peersman (2013): "Dissecting the dynamics of the $\{$ US $\}$ trade balance in an estimated equilibrium model," Journal of International Economics, 90(2), $302-315$. 
JACOBI, L., And J. Kluve (2006): "Before and After the Hartz Reforms: The Performance of Active Labour Market Policy in Germany," Journal for Labour Market Research, 40(1).

Kohaut, S., and C. Schnabel (2007): "Tarifliche ffnungsklauseln: Verbreitung, Inanspruchnahme und Bedeutung," Sozialer Fortschritt, 56(2).

Kollmann, R. (2002): "Monetary policy rules in the open economy: effects on welfare and business cycles," Journal of Monetary Economics, 49(5), 9891015 .

Kollmann, R., M. Ratto, W. Roeger, J. in't Veld, and L. Vogel (2015): "What drives the German current account? And how does it affect other EU member states?," Economic Policy, 30(81), 47-93.

Krause, M., D. Lopez-Salido, and T. LubiK (2008): "Inflation dynamics with search frictions: A structural econometric analysis," Journal of Monetary Economics, 55(5), 892-916.

Krebs, T., And M. Scheffel (2013): "Macroeconomic Evaluation of Labor Market Reform in Germany," IMF Working Paper, WP/13/42.

LütKePoHL, H. (2005): New introduction to multiple time series analysis. Springer.

Martins, O., S. Scarpetta, and D. Pilat (2003): "Mark-Up Ratios in Manufacturing Industries," OECD Economics Department Working Papers, 162.

Orphanides, A. (2001): "Monetary Policy Rules Based on Real-Time Data," American Economic Review, 91(4), 964-985.

Pesaran, M. H., T. Schuermann, and S. M. Weiner (2004): "Modelling Regional Interdependencies Using a Global Error-Correcting Macroeconometric Model," Journal of Business \& Economic Statistics, 22(2), 129-162.

Pissarides, C. A., And B. Petrongolo (2001): "Looking into the Black Box: A Survey of the Matching Function," Journal of Economic Literature, 39(2), 390-431.

Ravenna, F., and C. E. Walsh (2011): "Welfare-based optimal monetary policy with unemployment and sticky prices: A linear-quadratic framework," AEJ Macroeconomics, 3(2), 130-162.

Rotemberg, J. (1982): "Monopolisitic Price Adjustment and Aggregate Output ," Review of Economic Studies, 49(4), 517-531. 
Rubio-Ramirez, J. F., D. Waggoner, and T. Zha (2011): "Structural Vector Autoregressions: Theory of Identifcation and Algorithms for Inference," Review of Economic Studies, 77, 665-696.

Sabbatini, R., and F. Zollino (2010): "Macroeconomic trends and reforms in Germany," PSL Quarterly Review, 63(254), 235-263.

SchmitT-Grohe, S., And M. Uribe (2003): "Closing small open economy models," Journal of International Economics, 61(1), 163-185.

Smets, F., And R. Wouters (2007): "Shocks and Frictions in U.S. Business Cycles: A Bayesian DSGE Approach," American Economic Review, 97(3), 586-606.

Smith, V. L., And A. Galesi (2011): "GVAR Toolbox 1.1," www.cfap.jbs.cam.ac.uk/research/gvartoolbox.

Uhlig, H. (2005): "What are the Effects of Monetary Policy on Output? Results from an Agnostic Identification Procedure," Journal of Monetary Economics, $52(2), 381-419$.

Vissing-Jorgensen, A. (2002): "Limited asset market participation and the elasticity of intertemporal substitution," NBER Working paper Series, (8896).

Vogel, L. (2011): "Structural reforms and external rebalancing in the euro area: a model-based analysis," European Commission, European Economy. Economic Papers, (443).

Weber, A. (2000): "Vacancy durations - a model for employers search," Applied Economics, 32, 1069-1075.

Wyplosz, C. (2013): "Eurozone Crisis: Its About Demand, not Competitiveness," The Graduate Institute, Geneva.

Yashiv, E. (2000): "The Determinants of Equilibrium Unemployment," American Economic Review, 90(5), 1297-1322. 


\section{Online Appendix}

\section{A Data}

We test every series for seasonality using the testing procedure outlined in Smith and Galesi (2011) and adjust all series with a seasonal component by employing the X12-ARIMA method. We allow the software to correct for additive outliers. All series are obtained in quarterly frequency. Exceptions are explicitly mentioned in this section. When necessary, we interpolate data using the Boots, Feibes, and Lisman (1967) methodology.

\section{- Real GDP}

We employ real GDP series from the OECD (Ecowin: oe:(country code)_gdpvq).

\section{- CPI/Inflation}

All CPI series are obtained from the OECD database (Ecowin: oecd:(country code)_cpaltt01_ixobq).

\section{- Real Wage}

We use compensation of employees data (Ecowin: oe:aut_wsssq) and the total number of employees data (Ecowin: oecd:(country code)_emeytths_stsaq) from the OECD database to compute the compensation per employee. Exceptions are compensation series for Greece, Netherlands and Portugal (Ecowin: oe:(country code)_wsssa) as well as number of employees data for Greece and the Netherlands (ana:(country code)_eem_per) where we extend the quarterly series with interpolated annual data. We deflate these series with the CPI to get a measure of real wages.

\section{- Unemployment Rate}

Unemployment rate data (Ecowin: oecd:(country code)_unrtsutt_stsaq) comes from the OECD database. We complete the Greek series with interpolated annual data (Ecowin: oecd:(country code)_unrtsutt_stsaa).

\section{- REER}

We use the real effective exchange rate series from the IMF IFS database. (Ecowin: ifs:s(country code)00reczfq)

\section{- Current Account Balance}

We use the current account balance from the OECD online database and the nominal GDP (Ecowin: oe:(country code)_gdpq) from the OECD database (Ecowin) to construct the current account balance to GDP ratio. 
- Interest Rate

The source for the German nominal short-term interest rate (money market rate) is the IMF IFS database (Ecowin: ifs:s(country code)60b00zfq).

\section{- Trade Data}

We use the Directions of Trade statistics from the IMF in annual frequency to compute the trade weight matrix. 


\section{B Solution of the bargaining problem}

\section{B.1 Wages}

Taking logs of the Nash product

$$
\left(\frac{\zeta_{t}^{k}}{\lambda_{t}^{k}}\right)^{\eta_{t}^{k}} \mu_{t}^{k^{1-\eta_{t}^{k}}}
$$

yields

$$
\eta_{t}^{k} \ln \left(\frac{\zeta_{t}^{k}}{\lambda_{t}^{k}}\right)+\left(1-\eta_{t}^{k}\right) \ln \mu_{t}^{k}
$$

Differentiating with respect to $W_{t}^{k}$ gives

$$
\eta_{t}^{k} \frac{1}{\left(\frac{\zeta_{t}^{k}}{\lambda_{t}^{k}}\right)} \frac{\partial\left(\frac{\zeta_{t}^{k}}{\lambda_{t}^{k}}\right)}{\partial W_{t}^{k}}+\frac{1}{\mu_{t}^{k}} \frac{\partial \mu_{t}^{k}}{\partial W_{t}^{k}}=0 .
$$

or

$$
\eta_{t}^{k} \mu_{t}^{k} \frac{\partial\left(\frac{\zeta_{t}^{k}}{\lambda_{t}^{k}}\right)}{\partial W_{t}^{k}}=-\left(1-\eta_{t}^{k}\right)\left(\frac{\zeta_{t}^{k}}{\lambda_{t}^{k}}\right) \frac{\partial \mu_{t}^{k}}{\partial W_{t}^{k}} .
$$

First order conditions with respect to $W_{t}^{k}$ and $H_{t}^{k}$ are thus given by

$$
\begin{aligned}
\frac{\partial \mu_{t}^{k}}{\partial W_{t}^{k}} & =-\chi_{t}^{k} H_{t}^{k} \\
\frac{\partial\left(\frac{\zeta_{t}^{k}}{\lambda_{t}^{k}}\right)}{\partial W_{t}^{k}} & =H_{t}^{k} \\
\frac{\partial \mu_{t}^{k}}{\partial H_{t}^{k}} & =-W_{t}^{k} \chi_{t}^{k}+m c_{t}^{k} A_{t}^{k} v^{2} N_{t}^{k^{v-1}} H_{t}^{k^{v-1}} \\
\frac{\partial\left(\frac{\zeta_{t}^{k}}{\lambda_{t}^{k}}\right)}{\partial H_{t}^{k}} & =W_{t}^{k}-\frac{1}{\lambda_{t}^{k}} \epsilon_{t}^{k^{L}} \epsilon_{t}^{k^{P}} H_{t}^{\varphi}
\end{aligned}
$$

Since $\frac{\partial \mu_{t}^{k}}{\partial W_{t}^{k}}=-\chi_{t}^{k} H_{t}^{k}$ and $\frac{\partial\left(\frac{\zeta_{t}^{k}}{\lambda_{t}^{k}}\right)}{\partial W_{t}^{k}}=H_{t}^{k}$, we get the sharing rule 


$$
\eta_{t}^{k} \mu_{t}^{k}=\left(1-\eta_{t}^{k}\right) \chi_{t}^{k}\left(\frac{\zeta_{t}^{k}}{\lambda_{t}^{k}}\right)
$$

Plugging in the equations for $\mu_{t}^{k}$ and $\zeta_{t}^{k}$ yields

$$
\begin{aligned}
\eta_{t}^{k} \frac{\kappa}{q\left(\theta_{t}^{k}\right)}= & \left(1-\eta_{t}^{k}\right) \chi_{t}^{k}\left(W_{t}^{k} H_{t}^{k}-b^{k}-\frac{1}{\lambda_{t}^{k}} \epsilon_{t}^{k^{L}} \epsilon_{t}^{k^{P}} \frac{H_{t}^{k^{1+\varphi}}}{1+\varphi}\right. \\
& \left.+E_{t}\left[\beta(1-\rho)\left(1-\theta_{t+1}^{k} q\left(\theta_{t+1}^{k}\right)\right) \frac{\zeta_{t+1}^{k}}{\lambda_{t+1}^{k}}\right]\right)
\end{aligned}
$$

As the sharing rule must also hold in the future, we get

$$
\eta_{t+1}^{k} \mu_{t+1}^{k}=\left(1-\eta_{t+1}^{k}\right) \chi_{t+1}^{k} \frac{\zeta_{t+1}^{k}}{\lambda_{t+1}^{k}}
$$

or

$$
\frac{\eta_{t+1}^{k}}{\left(1-\eta_{t+1}^{k}\right)} \frac{1}{\chi_{t+1}^{k}} \mu_{t+1}^{k}=\frac{\eta_{t+1}^{k}}{\left(1-\eta_{t+1}^{k}\right)} \frac{1}{\chi_{t+1}^{k}} \frac{\kappa}{q\left(\theta_{t+1}^{k}\right)}=\frac{\zeta_{t+1}^{k}}{\lambda_{t+1}^{k}} .
$$

Plugging (B13) into (B11) yields

$$
\begin{aligned}
\eta_{t}^{k} \frac{\kappa}{q\left(\theta_{t}^{k}\right)}= & \left(1-\eta_{t}^{k}\right) \chi_{t}^{k}\left(W_{t}^{k} H_{t}^{k}-b^{k}-\frac{1}{\lambda_{t}^{k}} \epsilon_{t}^{k^{L}} \epsilon_{t}^{k^{P}} \frac{H_{t}^{k^{1+\varphi}}}{1+\varphi}\right. \\
& \left.+E_{t}\left[\beta(1-\rho)\left(1-\theta_{t+1}^{k} q\left(\theta_{t+1}^{k}\right)\right) \frac{\eta_{t+1}^{k}}{\left(1-\eta_{t+1}^{k}\right)} \frac{1}{\chi_{t+1}^{k}} \frac{\kappa}{q\left(\theta_{t+1}^{k}\right)}\right]\right)
\end{aligned}
$$

Rearranging gives

$$
\begin{aligned}
\frac{\eta_{t}^{k}}{\left(1-\eta_{t}^{k}\right)} \frac{1}{\chi_{t}^{k}} \frac{\kappa}{q\left(\theta_{t}^{k}\right)}= & W_{t}^{k} H_{t}^{k}-b^{k}-\frac{1}{\lambda_{t}^{k}} \epsilon_{t}^{k^{L}} \epsilon_{t}^{k^{P}} \frac{H_{t}^{k^{1+\varphi}}}{1+\varphi} \\
& +E_{t}\left[\beta(1-\rho)\left(1-\theta_{t+1}^{k} q\left(\theta_{t+1}^{k}\right)\right) \frac{\eta_{t+1}^{k}}{\left(1-\eta_{t+1}^{k}\right)} \frac{1}{\chi_{t+1}^{k}} \frac{\kappa}{q\left(\theta_{t+1}^{k}\right)}\right] .
\end{aligned}
$$

Solving for the wage yields 


$$
W_{t}^{k} H_{t}^{k}=\delta_{t}^{k}+b^{k}+\frac{1}{\lambda_{t}^{k}} \epsilon_{t}^{k^{L}} \epsilon_{t}^{k^{P}} \frac{H_{t}^{k^{1+\varphi}}}{1+\varphi}-E_{t}\left[\beta(1-\rho)\left(1-\theta_{t+1}^{k} q\left(\theta_{t+1}^{k}\right)\right) \delta_{t+1}^{k}\right]
$$

where

$$
\delta_{t}^{k}=\frac{\eta_{t}^{k}}{\left(1-\eta_{t}^{k}\right)} \frac{1}{\chi_{t}^{k}} \frac{\kappa}{q\left(\theta_{t}^{k}\right)}
$$

\section{B.2 Hours}

As before, we take logs of the Nash product and differentiate now with respect to $H_{t}$ :

$$
\eta_{t}^{k} \mu_{t}^{k} \frac{\partial\left(\frac{\zeta_{t}^{k}}{\lambda_{t}^{k}}\right)}{\partial H_{t}^{k}}=-\left(1-\eta_{t}^{k}\right)\left(\frac{\zeta_{t}^{k}}{\lambda_{t}^{k}}\right) \frac{\partial \mu_{t}^{k}}{\partial H_{t}^{k}}
$$

Multiplying both sides by $-\chi_{t}$ yields

$$
-\chi_{t}^{k} \eta_{t}^{k} \mu_{t}^{k} \frac{\partial\left(\frac{\zeta_{t}^{k}}{\lambda_{t}^{k}}\right)}{\partial H_{t}^{k}}=\left(1-\eta_{t}^{k}\right) \chi_{t}^{k}\left(\frac{\zeta_{t}^{k}}{\lambda_{t}^{k}}\right) \frac{\partial \mu_{t}^{k}}{\partial H_{t}^{k}}
$$

Using equation (B10), we get

$$
-\chi_{t}^{k} \frac{\partial\left(\frac{\zeta_{t}^{k}}{\lambda_{t}^{k}}\right)}{\partial H_{t}^{k}}=\frac{\partial \mu_{t}^{k}}{\partial H_{t}^{k}}
$$

We now plug in the values and get

$$
-\chi_{t}^{k} W_{t}^{k}+\chi_{t}^{k} \frac{1}{\lambda_{t}^{k}} \epsilon_{t}^{k^{L}} \epsilon_{t}^{k^{P}} H_{t}^{k^{\varphi}}=-\chi_{t}^{k} W_{t}^{k}+m c_{t}^{k} A_{t}^{k} v^{2} N_{t}^{k^{v-1}} H_{t}^{k^{v-1}} .
$$

Rearranging yields our final equation for hours

$$
H_{t}^{k}=\left(\frac{m c_{t}^{k} A_{t}^{k} v^{2} N_{t}^{k^{v-1}}}{\chi_{t}^{k} \epsilon_{t}^{k^{L}} \epsilon_{t}^{k^{P}}} \lambda_{t}^{k}\right)^{\frac{1}{1+\varphi-v}}
$$

which differs from the one obtained by Krause, Lopez-Salido, and Lubik (2008), because hours do in our open economy model depend on $\chi_{t}^{k}$. 


\section{Steady State}

We assume that in steady state $\pi=1, p i^{*}=1, B=0, e=1, q=1$ and $C_{w}=C$.

$$
\begin{aligned}
& \lambda=(1-\omega)^{-\sigma} C^{-\sigma} \\
& \beta=\frac{1}{R} \\
& Y=(N H)^{v} \\
& m c=\frac{\epsilon-1}{\epsilon} \\
& M=\bar{m} S^{\nu} V^{1-\nu} \\
& S=1-(1-\rho) N \\
& N=(1-\rho) N+M \\
& \theta=V / S \\
& q(\theta)=M / V \\
& \frac{\kappa}{q(\theta)}=\beta \frac{\kappa}{q(\theta)}(1-\rho)+\operatorname{mc} \nu N^{(\nu-1)} H^{\nu}-W H \\
& W H=\delta+b+\frac{1}{\lambda} \frac{H^{(1+\varphi)}}{(1+\varphi)}-\beta(1-\rho)(1-\theta q(\theta)) \delta \\
& \delta=\frac{\eta}{(1-\eta)} \frac{1}{\chi} \frac{\kappa}{q(\theta)} \\
& H=\left(\operatorname{mc} v^{2} N^{(v-1)} \lambda\right)^{(1 /(1+\varphi-v))} \\
& Y=C+\kappa V
\end{aligned}
$$




\section{IRFs in the DSGE model with parameter un- certainty}

Figure 12: Technology shock under parameter uncertainty (pre-EMU model)
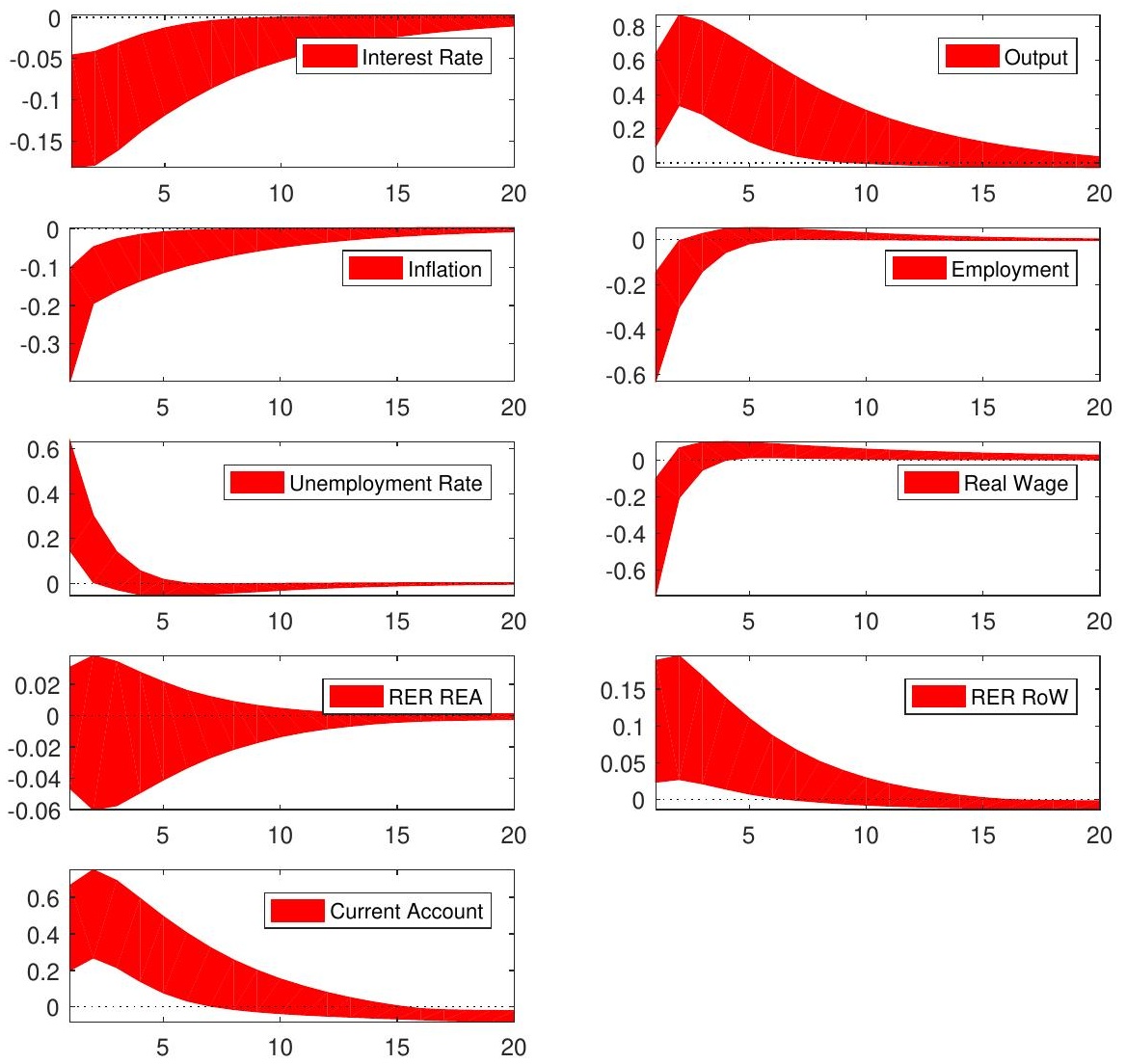

Note: The shaded area denotes the $10 \%$ to $90 \%$ range of impulse responses for the 10,000 draws. 
Figure 13: Technology shock under parameter uncertainty (EMU model)
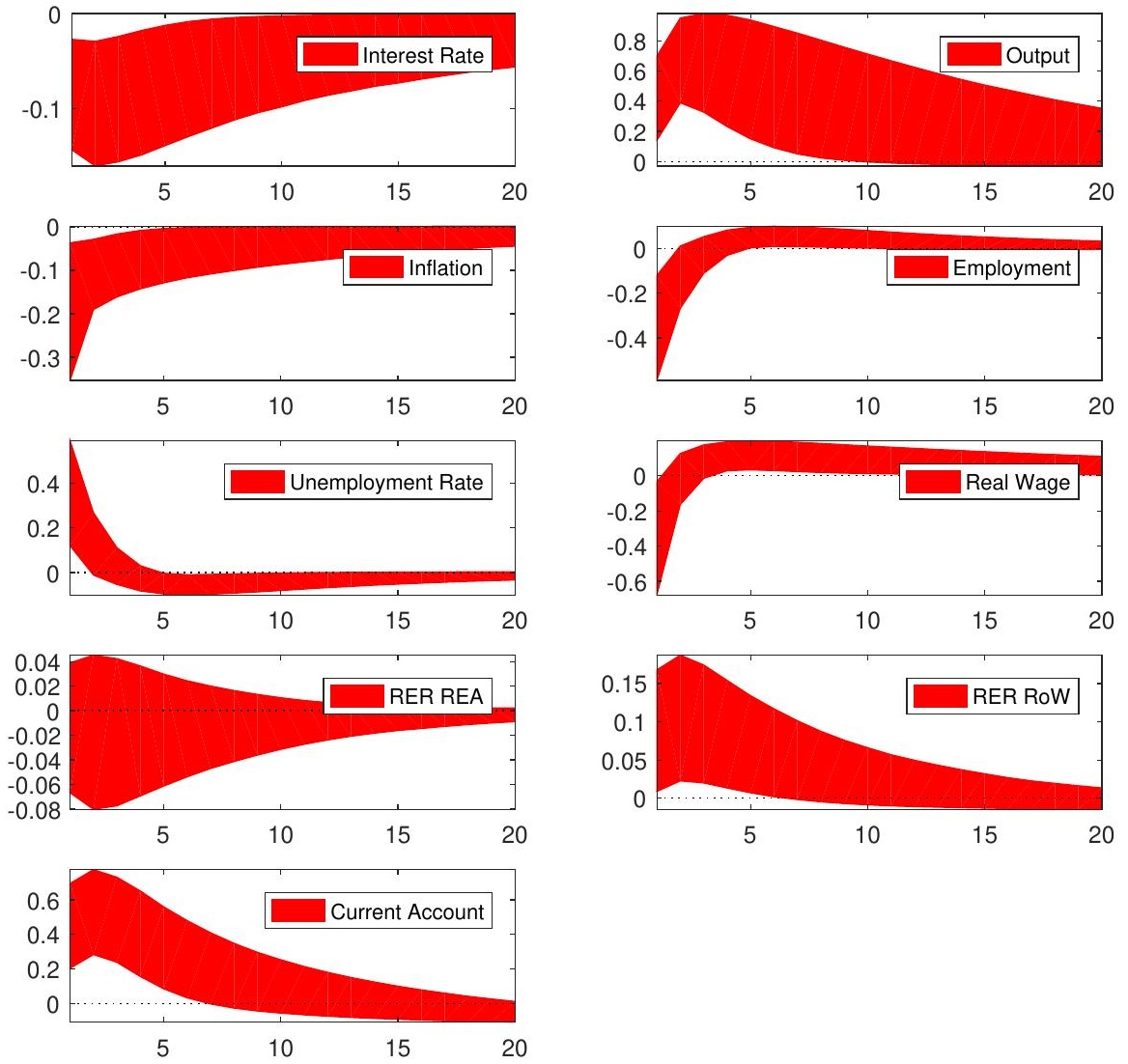

Note: The shaded area denotes the $10 \%$ to $90 \%$ range of impulse responses for the 10,000 draws. 
Figure 14: Preference shock under parameter uncertainty (pre-EMU model)
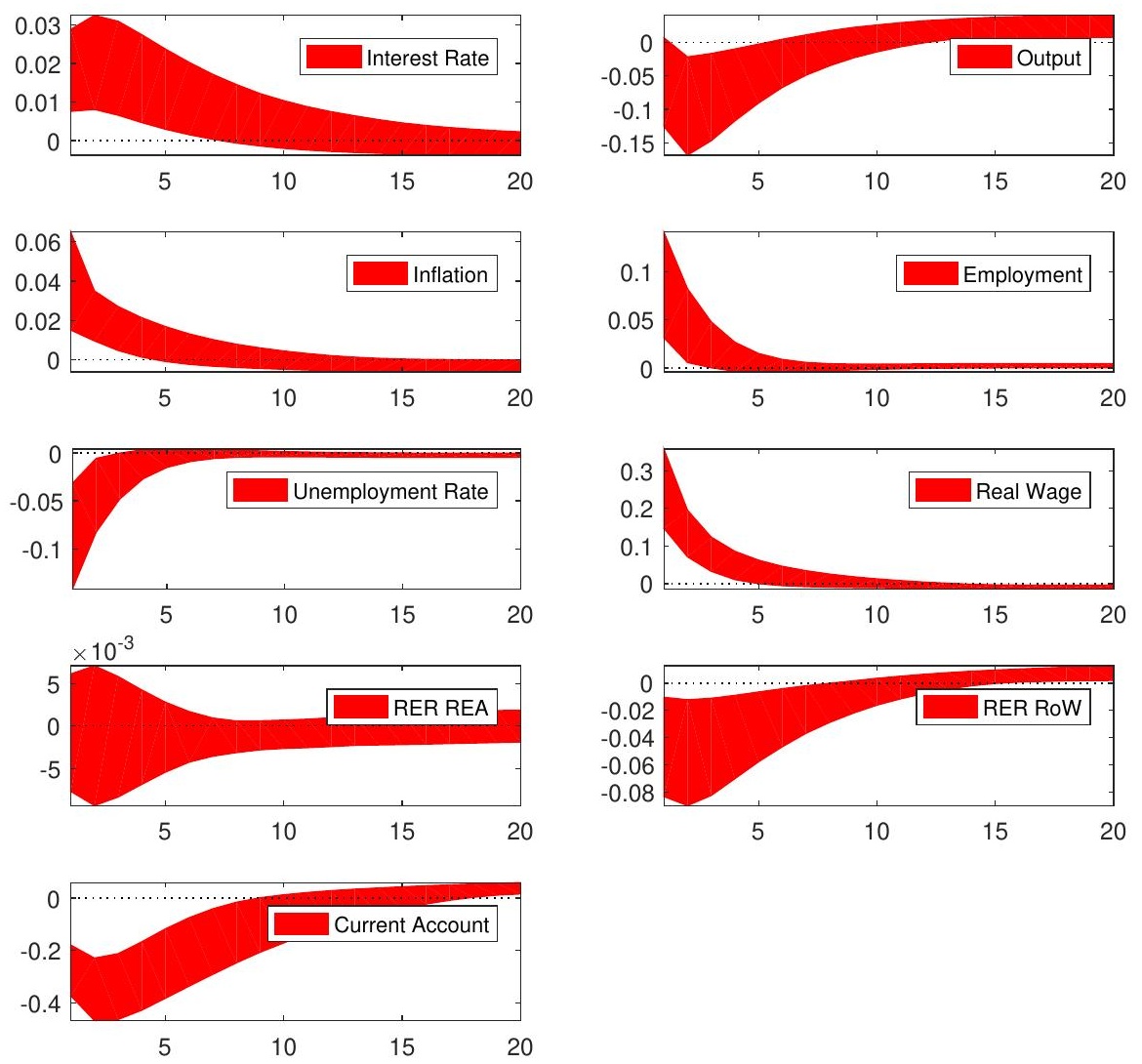

Note: The shaded area denotes the $10 \%$ to $90 \%$ range of impulse responses for the 10,000 draws. 
Figure 15: Preference shock under parameter uncertainty (EMU model)
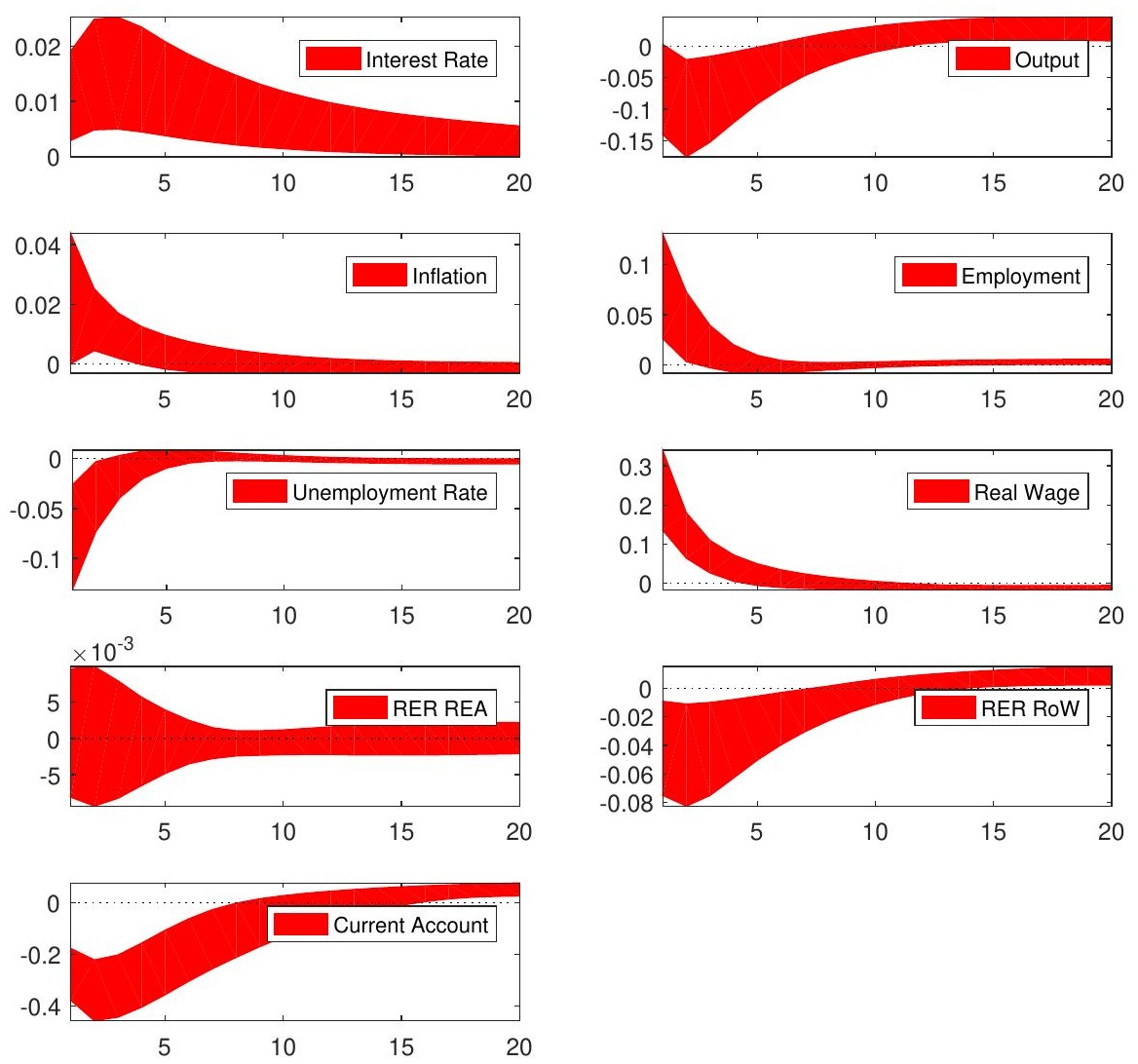

Note: The shaded area denotes the $10 \%$ to $90 \%$ range of impulse responses for the 10,000 draws. 
Figure 16: Monetary policy shock under parameter uncertainty (pre-EMU model)
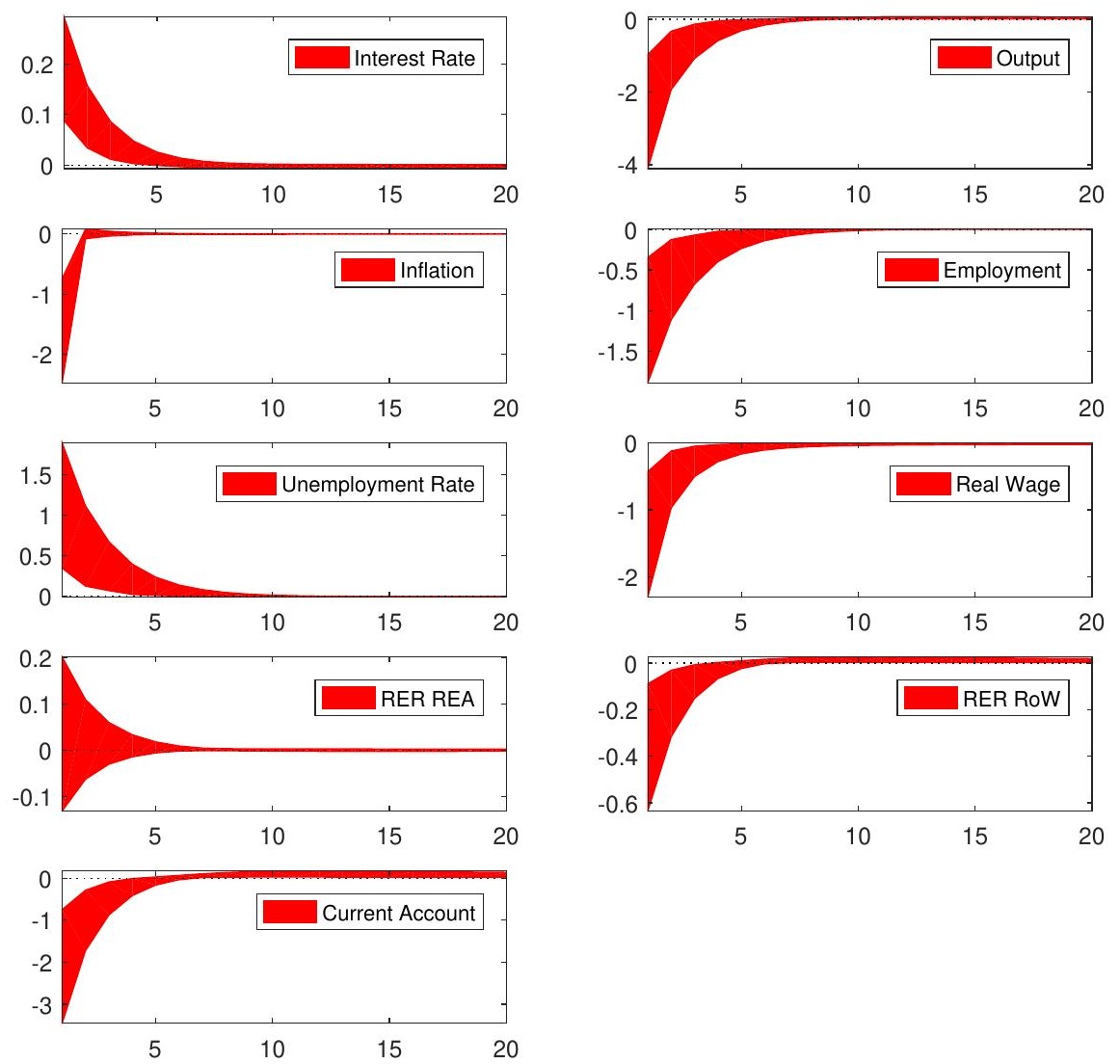

Note: The shaded area denotes the $10 \%$ to $90 \%$ range of impulse responses for the 10,000 draws. 
Figure 17: Monetary policy shock under parameter uncertainty (EMU model)
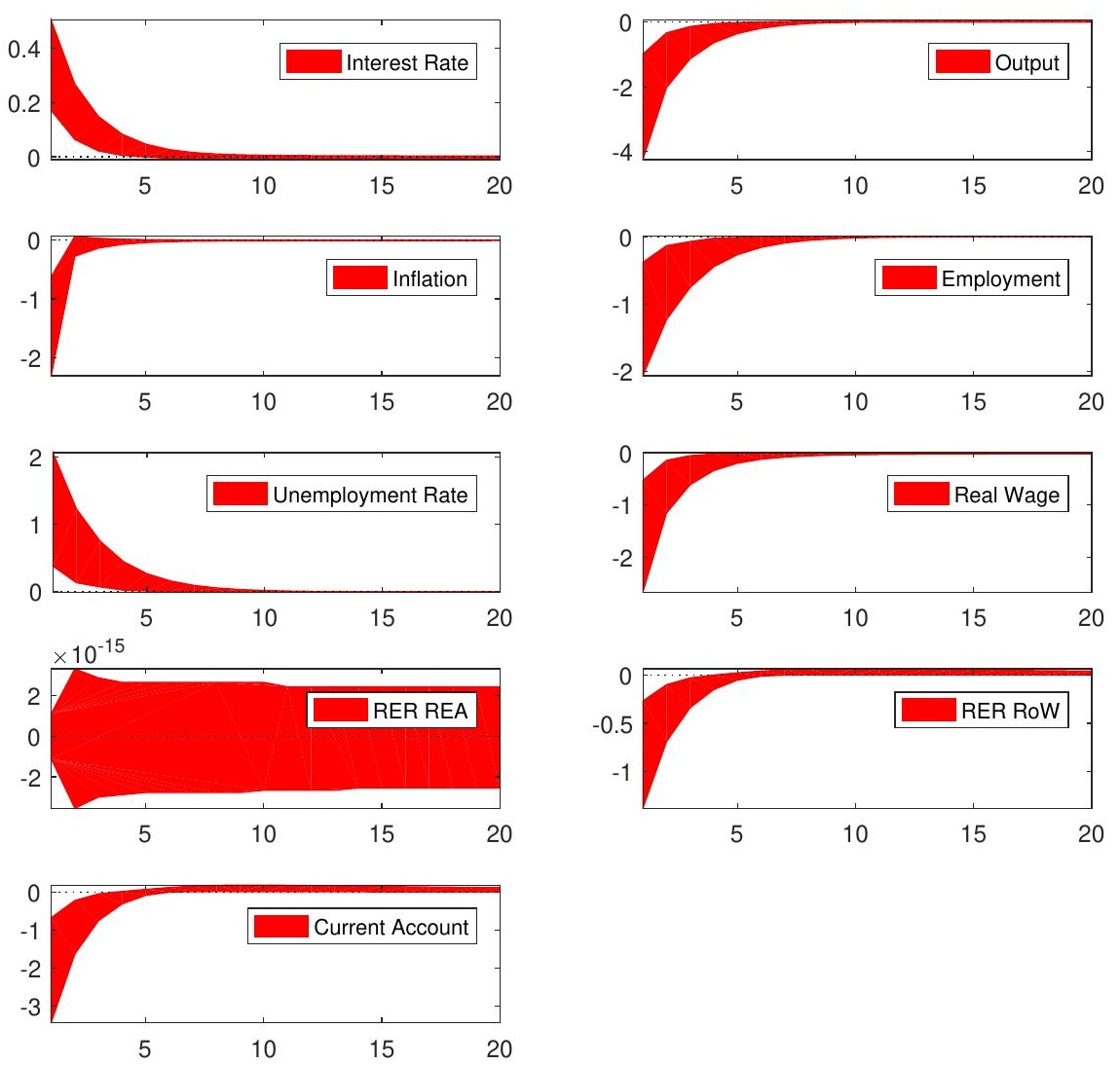

Note: The shaded area denotes the $10 \%$ to $90 \%$ range of impulse responses for the 10,000 draws. 
Figure 18: Labor supply shock under parameter uncertainty (pre-EMU model)
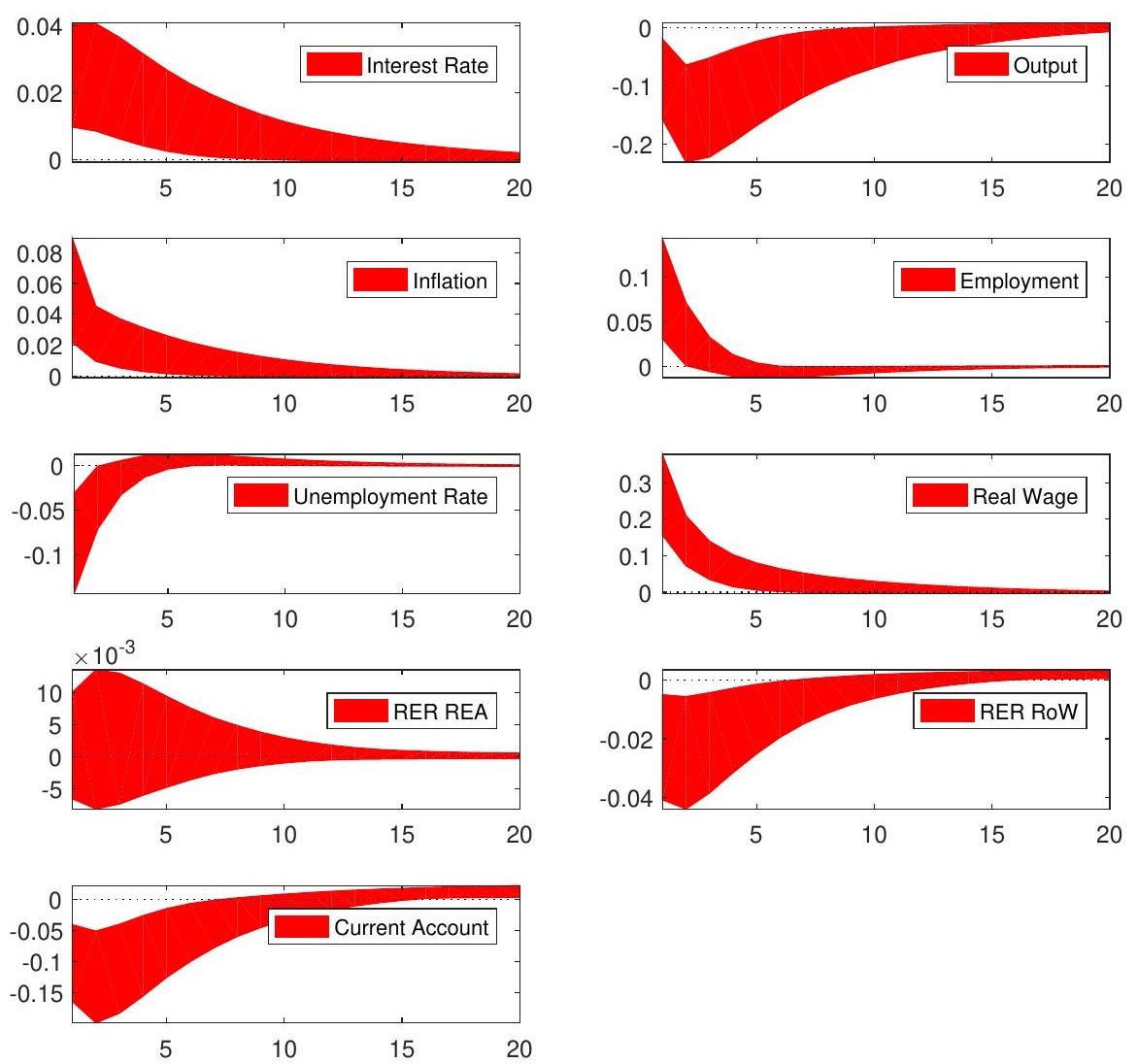

Note: The shaded area denotes the $10 \%$ to $90 \%$ range of impulse responses for the 10,000 draws. 
Figure 19: Labor supply shock under parameter uncertainty (EMU model)
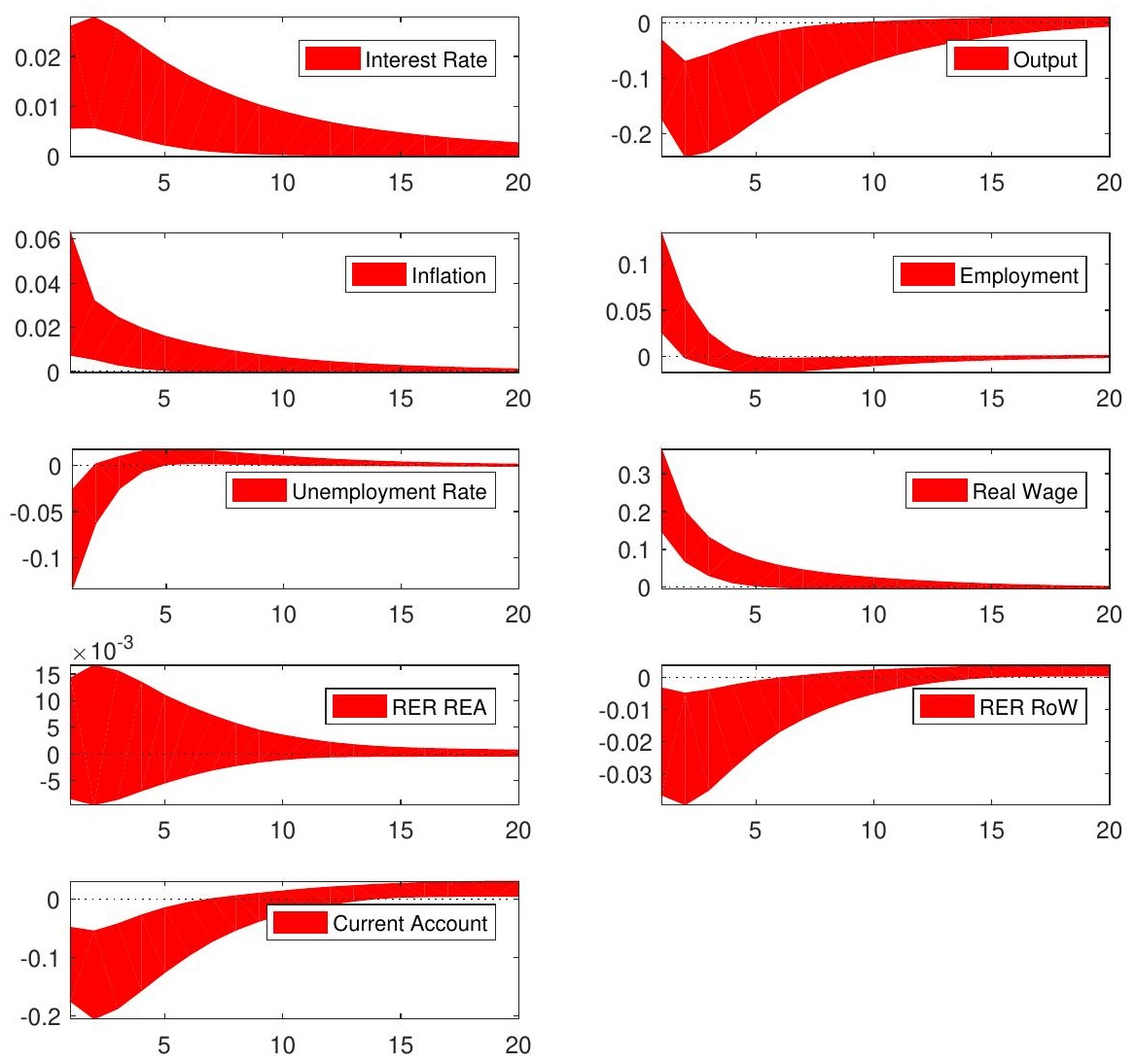

Note: The shaded area denotes the $10 \%$ to $90 \%$ range of impulse responses for the 10,000 draws. 
Figure 20: Persistent shock to bargaining power under parameter uncertainty (pre-EMU model, $\rho_{\eta}=0.99$ )
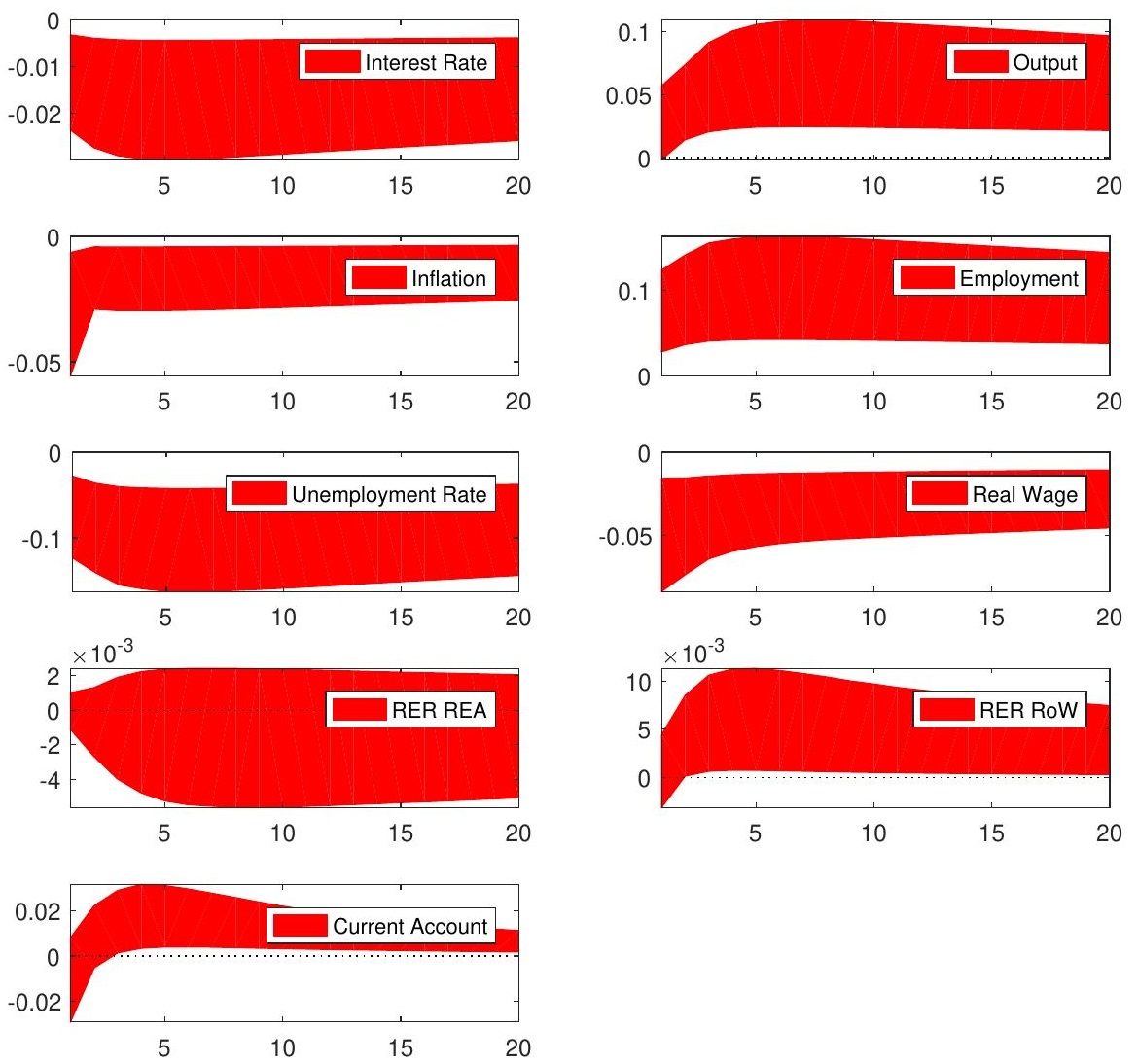

Note: The shaded area denotes the $10 \%$ to $90 \%$ range of impulse responses for the 10,000 draws. 
Figure 21: Persistent shock to matching efficiency under parameter uncertainty (pre-EMU model, $\rho_{m}=0.99$ )
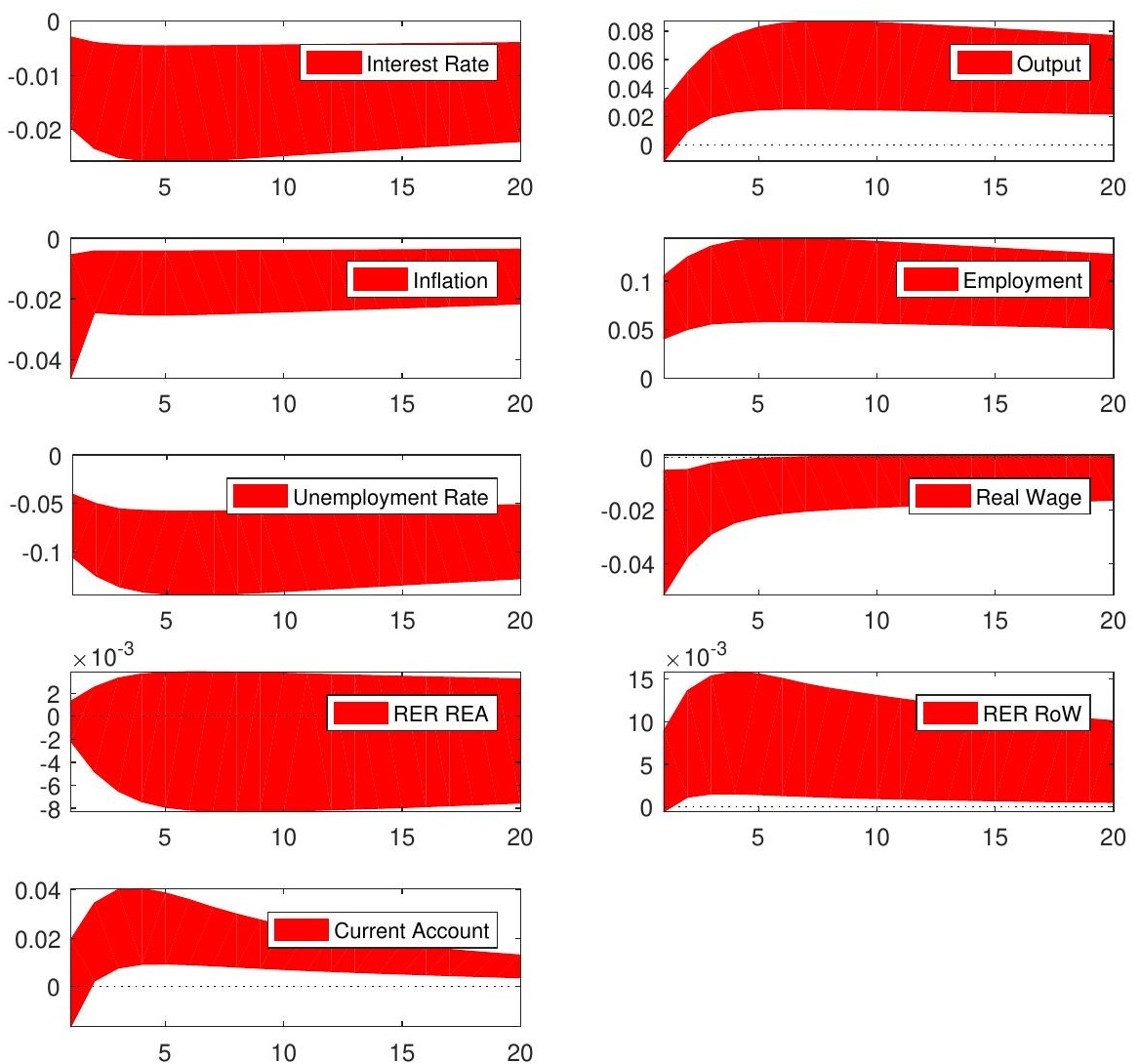

Note: The shaded area denotes the $10 \%$ to $90 \%$ range of impulse responses for the 10,000 draws. 
Figure 22: Persistent shock to bargaining power under parameter uncertainty (EMU model, $\rho_{\eta}=0.99$ )
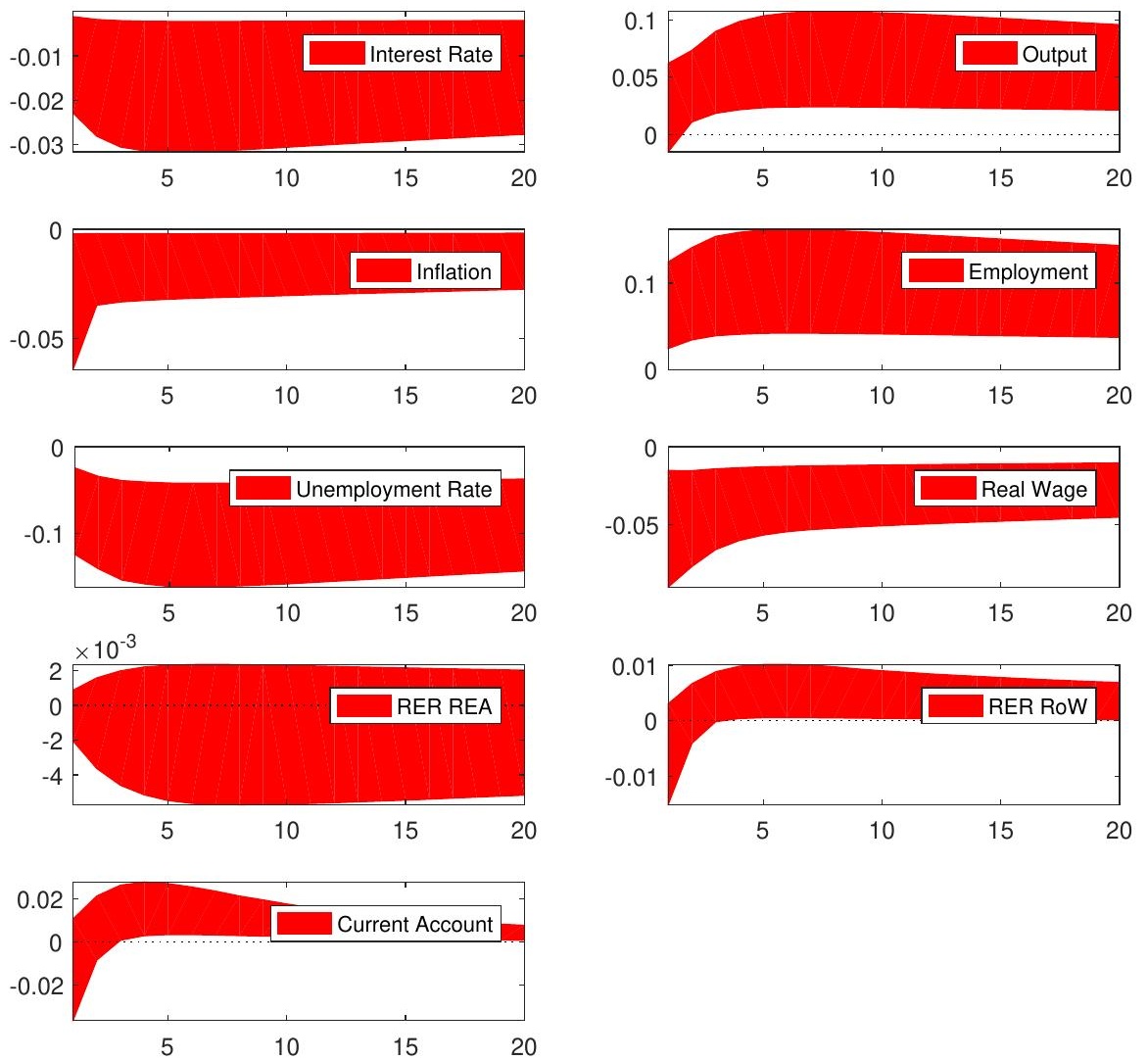

Note: The shaded area denotes the $10 \%$ to $90 \%$ range of impulse responses for the 10,000 draws. 
Figure 23: Persistent shock to matching efficiency under parameter uncertainty (EMU model, $\rho_{m}=0.99$ )
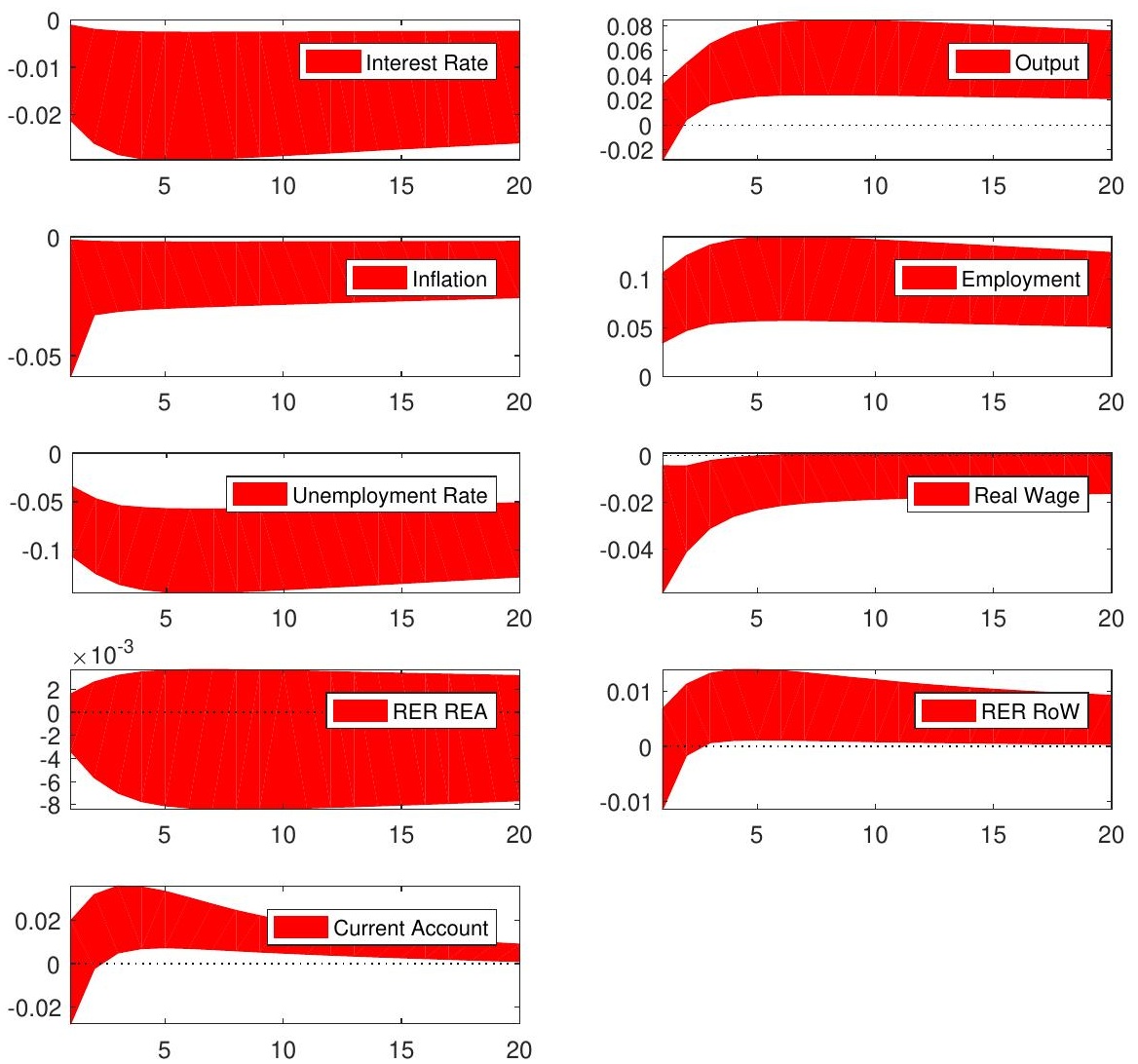

Note: The shaded area denotes the $10 \%$ to $90 \%$ range of impulse responses for the 10,000 draws. 
Figure 23: Persistent shock to matching efficiency under parameter uncertainty (EMU model, $\rho_{m}=0.99$ )
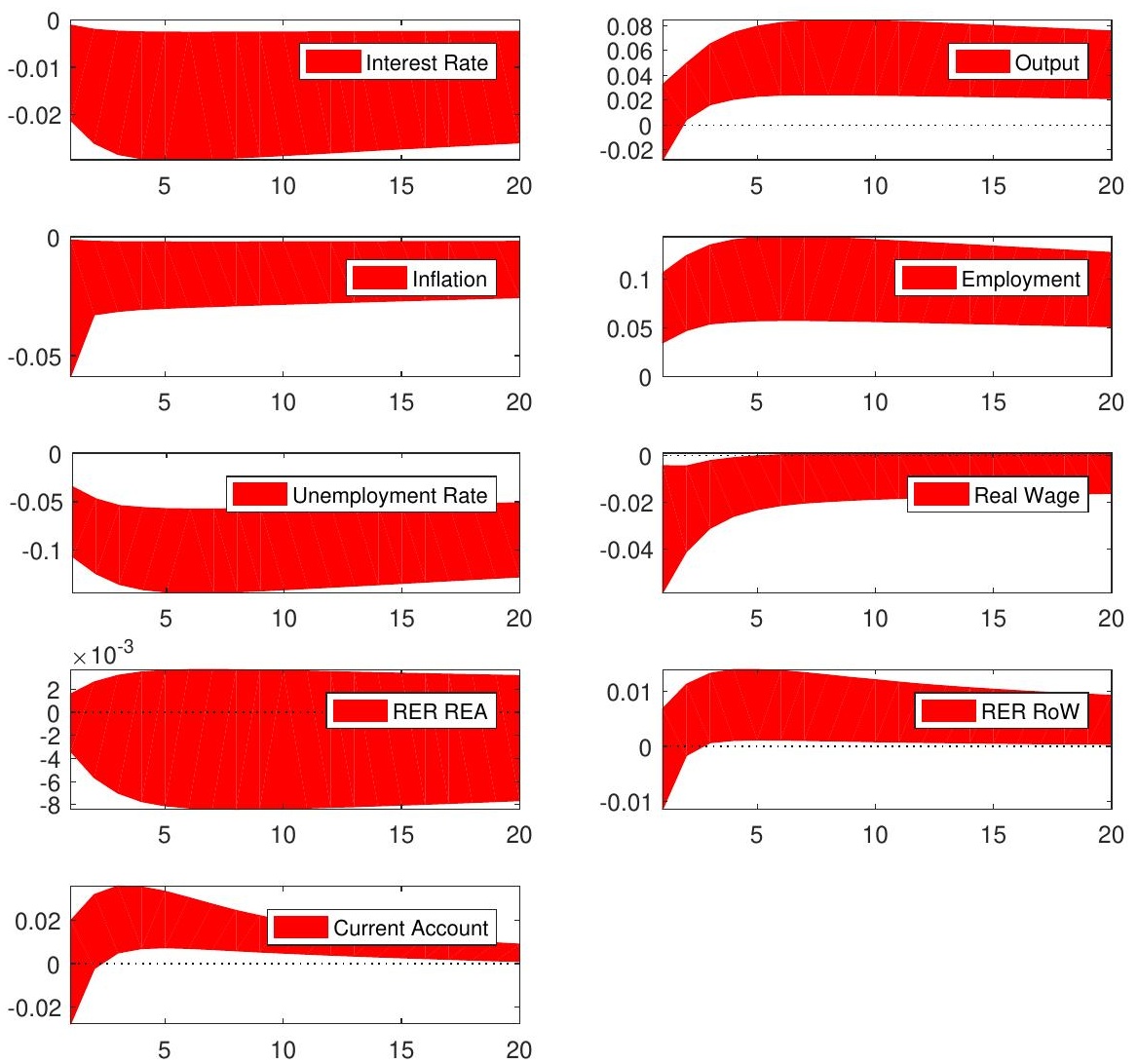

Note: The shaded area denotes the $10 \%$ to $90 \%$ range of impulse responses for the 10,000 draws. 